\title{
Streamflow recession patterns can help unravel the role of climate and humans in landscape co-evolution
}

\author{
Patrick W. Bogaart ${ }^{1}$, Ype van der Velde ${ }^{2}$, Steve W. Lyon $^{3}$, and Stefan C. Dekker ${ }^{1}$ \\ ${ }^{1}$ Copernicus Institute for Sustainable Development, Utrecht University, Utrecht, the Netherlands \\ ${ }^{2}$ Department of Earth Sciences, Faculty of Earth and life Sciences, VU University Amsterdam, Amsterdam, the Netherlands \\ ${ }^{3}$ Department of Physical Geography, Stockholm University, Stockholm, Sweden \\ Correspondence to: P. W. Bogaart (pwbogaart@gmail.com)
}

Received: 24 August 2015 - Published in Hydrol. Earth Syst. Sci. Discuss.: 25 September 2015

Revised: 11 February 2016 - Accepted: 16 March 2016 - Published: 15 April 2016

\begin{abstract}
Traditionally, long-term predictions of river discharges and their extremes include constant relationships between landscape properties and model parameters. However, due to the co-evolution of many landscape properties more sophisticated methods are necessary to quantify future landscape-hydrological model relationships. As a first step towards such an approach we use the Brutsaert and Nieber (1977) analysis method to characterize streamflow recession behaviour of $\approx 200$ Swedish catchments within the context of global change and landscape co-evolution. Results suggest that the Brutsaert-Nieber parameters are strongly linked to the climate, soil, land use, and their interdependencies. Many catchments show a trend towards more non-linear behaviour, meaning not only faster initial recession but also slower recession towards base flow. This trend has been found to be independent from climate change. Instead, we suggest that land cover change, both natural (restoration of natural soil profiles in forested areas) and anthropogenic (reforestation and optimized water management), is probably responsible. Both change types are characterised by system adaptation and change, towards more optimal ecohydrological conditions, suggesting landscape co-evolution is at play. Given the observed magnitudes of recession changes during the past 50 years, predictions of future river discharge critically need to include the effects of landscape co-evolution. The interconnections between the controls of land cover and climate on river recession behaviour, as we have quantified in this paper, provide first-order handles to do so.
\end{abstract}

\section{Introduction}

River runoff is a key component of the Earth system, performing functions that include energy transfer between the geosphere and the atmosphere, sustaining vegetation growth, transport of sediments and nutrients, and providing drinking water for humanity. Therefore, fresh water has been identified as one of nine planetary boundaries that define a safe operating space for mankind (Rockström et al., 2009; Steffen et al., 2015; Jaramillo and Destouni, 2015). Key questions in defining this safe operating space are how terrestrial precipitation is divided between evapotranspiration, storage in biomass, soil and subsurface, and river runoff, and how this division is affected by climate change and human actions. Answering these questions means facing the complexity and multitude of interactions between soil, vegetation, atmosphere, and humans. Therefore, several recent opinion papers in hydrology called for the use of "Darwinian" approaches that try to summarise the effects of co-evolution between soil, vegetation, atmosphere, and humans on the hydrological cycle into general emergent patterns, and use these emergent patterns to explain the origin of the observed variations (Harman and Troch, 2014; Sivapalan et al., 2011; Savenije et al., 2014; Schaefli et al., 2011; Troch et al., 2013b, 2015).

Humans impact river discharge dynamics in many ways, either directly (e.g. diversions, dams and reservoirs, artificial drainage) or indirectly (e.g. deforestation, anthropogenic climate change) calling for an integrated socio-hydrological approach (Savenije et al., 2014). Sivapalan et al. (2012) described three avenues through which this human role in the 
hydrological cycle could be investigated: historical, comparative, and process investigation approaches. The credibility of process approaches such as agent-based modelling studies that explicitly describe the effects of human choices and interactions between humans and their environment on the hydrological cycle, critically depends on parameterizations derived from historical and comparative data investigation studies. Thorough (re)analysis of observations in a coevolutionary context, taking into account all correlations and interactions between soil, vegetation, climate, and humans, is thus needed.

In this paper we combine a deterministic "Newtonian" approach to derive and interpret river basin storage-discharge relationships and trends thereof with a Darwinian approach that relates these river basin storage-discharge relationships to landscape and climate characteristics. From these emergent patterns we aim to infer the climate and human impact on river basin storage-discharge relationships. We focus on the case of Sweden, because it provides both a strong climatic gradient, a wealth of data and numerous previous studies to build upon. Destouni et al. (2013) analysed river discharge changes in nine major catchments of Sweden since 1900 (historical investigation approach). They showed that both hydropower dams and agriculture increased evapotranspiration and reduced river discharge. Furthermore, hydropower dams decreased river discharge dynamics, while agriculture increased river discharge dynamics. Building on these results, van der Velde et al. (2013a) related yearly average evapotranspiration derived from 50-year water balances of over 300 catchments in Sweden to catchment characteristics such as land cover, topography, and soil type. They found evidence for strong increases in evapotranspiration flux of agricultural and forested areas in the southern half of Sweden, which they related to increased biomass production and improved drainage in both biomes. These results were corroborated regionally through water balance modelling work by Jaramillo et al. (2013).

Based on these studies, we hypothesize that human modifications to the natural system alter storage-discharge and associated recession dynamics of catchments directly or through co-evolution of soil, vegetation, climate, and landscape, which in turn change the annual evapotranspiration and discharge fluxes. Focussing on the first part of this hypothesis, in this paper we apply a combination of historical and comparative investigation approaches to quantify landscape, climate, and anthropogenic controls on river basin storage-discharge relationships. Specifically, we implement streamflow recession analysis as our analytical tool. Streamflow recessions, i.e. how catchments release water after a rainfall or snowmelt event, are typically analysed based on Boussinesq theory, which has been demonstrated to firmly link observed aquifer or catchment response to an underlying physical model, enabling the interpretation of model parameters (Brutsaert and Nieber, 1977; Troch et al., 2013a). Several studies have shown that these recession parameters change over time due to natural processes such as permafrost thaw (Lyon et al., 2009) and changing groundwater storage (Brutsaert, 2008). However, to date, no studies have investigated how human influence changed the river basin storagedischarge and stream recession dynamics in a regional setting. In this paper we aim to determine regional patterns in river recession behaviour, taking into account the correlations between soil, vegetation, atmosphere, and humans as a measure for landscape co-evolution, and unravel the natural and anthropogenic controls creating these patterns and changes thereof. We seek to empirically test the theoretical links between Brutsaert and Nieber (1977) recession parameters $a$ and $b$, catchment properties and forcing variables, as introduced below in Sect. 1.1 and 1.2. Special emphasis will be given to link spatial patterns and temporal trends in recession parameters to patterns and trends in external controls. For this, we apply recession analysis to streamflow observations from a large number of Swedish catchments, for the last 50 years.

\subsection{Theory}

Catchments can be regarded as (bio)physical systems that receive input in the form of precipitation $(P)$, which either adds to the amount of water stored $(S)$, or is lost as discharge $(Q)$ or evapotranspiration $(E)$. All hydrological theory therefore revolves about the water balance equation

$\mathrm{d} S / \mathrm{d} t=P-Q(S)-E(S)$.

Although Eq. (1) is essentially just a continuity equation, application of it to real-world systems is generally not possible because storage $S$ by itself is not directly measurable and the functions $Q(S)$ and $E(S)$ are often highly non-linear and depend on many factors, which are not always easily parameterized. Examples include hydraulic architecture on multiple scales (ranging from the porous soil medium, via macropores and preferential flow paths, to the stream network geomorphology) and plant physiological controls of transpiration.

Partly as a means to solve these issues, Brutsaert and Nieber (1977) demonstrated how information on storagedischarge relationships can be obtained by studying discharge recessions, i.e. the period after a rainfall or snowmelt event when water drains from a catchment. By plotting the time derivative of streamflow, $\mathrm{d} Q / \mathrm{d} t$, against streamflow $Q$ itself, all individual recession hydrographs overlap and the general recession behaviour can be studied by characterizing the recession data with the power-law model

$-\mathrm{d} Q / \mathrm{d} t=a Q^{b}$,

where the coefficient $a$ and the exponent $b$ are empirical parameters obtained through fitting.

In their analysis, Brutsaert and Nieber (1977) proceed by showing that the power-law model (Eq. 2) is linked to an underlying hydraulic process based on Darcy's law and var- 
Table 1. Analytical expressions for Brutsaert and Nieber (1977) recession parameters $a$ and $b$, for various conditions. Here, $k[L / T]$ is saturated hydraulic conductivity, $f[-]$ is drainable porosity (specific yield), $D[L]$ is active aquifer thickness (difference between initial phreatic surface and final drainage level), and $n$ is an exponent in the power-law conductivity model $k(z)=k_{D}(z / D)^{n}(\operatorname{Rupp}$ and Selker, 2005). $L[L]$ total length of the channel network, $A\left[L^{2}\right]$ catchment area, such that $L / A$ is drainage density, $p[-]$ is a linearisation parameter ( $p D$ reflects a "representative" water table height), $\alpha[-]$ is slope angle, and $B[L]$ is hillslope length. Note that $B$ is associated with the inverse of drainage density $L / A$.

\begin{tabular}{|c|c|c|c|c|c|}
\hline Model & Topography & Conductivity & $a$ & $b$ & Reference \\
\hline Non-linear Bouss. ${ }^{a}$ & Flat & Uniform & $1.133 / k f D^{3} L^{2}$ & 3 & Brutsaert and Nieber (1977) \\
\hline Non-linear Bouss. ${ }^{b}$ & Flat & Uniform & $4.8 k^{1 / 2} L / f A^{3 / 2}$ & 1.5 & Brutsaert and Nieber (1977) \\
\hline Non-linear Bouss. ${ }^{b}$ & Flat & Power-law & $\propto \frac{1}{f}\left[\frac{k_{D} L^{2}}{2^{n}(n+1) D^{n} A^{n+3}}\right]^{\frac{1}{n+2}}$ & $\frac{2 n+3}{n+2}$ & Rupp and Selker (2005) \\
\hline Non-linear Bouss ${ }^{b}$ & Sloping & Uniform & & 0 & Bogaart et al. (2013) \\
\hline Non-linear Bouss. ${ }^{b}$ & Sloping & Power law & & $\frac{2 n+1}{n+1}$ & Rupp and Selker (2006b) \\
\hline Linearized Bouss. & Flat & Uniform & $\pi^{2} k p D L^{2} / f A^{2}$ & 1 & Brutsaert and Nieber (1977) \\
\hline Linearized Bouss. & Sloping & Uniform & $2 k\left(p D \cos ^{2} \alpha+B \sin \alpha\right) / f B^{2}$ & 1 & Zecharias and Brutsaert (1988) \\
\hline Kinematic wave & Sloping & Uniform & & 0 & Bogaart et al. (2013) \\
\hline Kinematic wave & Sloping & Exp. decr. & & 2 & Troch et al. (1993) \\
\hline Weir & & & & 1.33 & Sect. C \\
\hline Channel flow & & & & $1-1.2$ & Sect. C \\
\hline
\end{tabular}

a "Early" time, i.e., right after sudden onset of drainage, when mainly the aquifer parts near the drainage channels contribute to base flow.

b "Late" time, i.e., when the whole aquifer contributes.

ious assumptions. For shallow, flat-lying aquifers with uniform conductivity, the predominantly horizontal free-surface groundwater flow can be approximated by the Boussinesq equation, or the linearised version thereof, which for this particular case can be solved analytically, yielding expressions for $a$ while keeping $b$ constant (see Table 1).

The power-law recession model Eq. (2) is consistent with a generalized class of storage-discharge models, i.e.

$Q=c S^{d}$,

where $S$ is "free" storage above some threshold $S_{0}$ (e.g. field capacity), $c=[a(2-b)]^{1 /(2-b)}$, and $d=1 /(2-b)$ (Clark et al., 2009), such that the linear recession model $b=1$ corresponds with the linear reservoir model $Q=a S$.

A useful characterisation of recession dynamics is the timescale involved. For linear reservoirs, $1 / a$ is equal to the $e$-folding time, but for non-linear reservoirs this is no longer the case. An alternative approach is to define the timescale for which half of the initial reservoir storage is depleted.

For a linear reservoir $(Q=a S)$, the recession equation $-\mathrm{d} Q / \mathrm{d} t=a Q$ can be integrated to yield $Q(t)=Q_{0} e^{-a t}$. Using $S=1 / a Q$ and defining time $T$ such that $S(T)=$ $1 / 2 S(0)$ yields

$T=\frac{1}{a} \ln 2$.

For non-linear reservoirs ( $b>1$ in Eq. 2), no closed solution for $T$ on the base of recession parameters $a$ and $b$ exists. We therefore chose to determine $T$ on the base of a characteristic discharge at the start of the recession, $Q_{0}$ (consistent with the initial storage mentioned above). After integrating
Eq. (2) and again solving for $T$, we yield

$T=\frac{Q_{0}^{1-b}}{a(b-1)}\left(2^{-\frac{1-b}{2-b}}-1\right)$.

An alternative approach was used by McMillan et al. (2014), who scale flow $Q$ by median flow $\bar{Q}$ to obtain nondimensional flow $\hat{Q}=Q / \bar{Q}$. Equation (2) can now be written as

$-\mathrm{d} \hat{Q} / \mathrm{d} t=\hat{Q}^{b} / T_{0}$,

where $T_{0}$ is a recession timescale at median flow.

Although in theory $1 / a, T$, and $T_{0}$ are different measures, and the units of $1 / a$ depend on the value of $b$, in practice these three measures are strongly correlated (see Fig. $4 \mathrm{~b}-\mathrm{d}$, discussed later).

\subsection{Physical interpretation}

Making assumptions on the effective (contributing) catchment area and aquifer depth, Brutsaert and Nieber (1977), in their pioneering work, applied results based on the non-linear Boussinesq equation (Table 1) to determine catchment-scale effective conductivity $k$ and drainable porosity $f$. Already in this first attempt, the results were interpreted in the context of land use as well: one outlier, that had an "anomalously" high value for $a$ (relative to expected values based on drainage density) was "undoubtedly [due] to the fact that that stream drains a large swamp".

Follow-up studies related $a$ to topographic slope and drainage density (Zecharias and Brutsaert, 1988) or aquifer depth $D$ (Troch et al., 1993). Recession-based estimation of 
$k$ or $k / f$ appeared to be difficult to compare with values based on soil samples, presumably because catchment-scale hydraulic conductivity is strongly influenced by macropores and other rapid flow paths not captured on the sample scale (i.e., Brooks et al., 2004). For this reason, Lyon and Troch (2007), in a related analysis, for example deliberately chose to apply hillslope-scale conductivity estimates.

Despite these difficulties, applications of the method have been reported for widely varying environments, ranging from virtual catchments (Szilagyi et al., 1998) to humid catchments in the Appalachians (Parlange et al., 2001), steep, fractured bedrock, semi-arid catchments (Mendoza et al., 2003) and tropical spring-fed catchments (Malvicini et al., 2005). Other studies investigated how recession parameters $a$ and $b$ change with geology (Tague and Grant, 2004), scale (Clark et al., 2009), and climate (van Dijk, 2010) or combinations thereof (Farmer et al., 2003; Beck et al., 2013; McMillan et al., 2014). At least for some catchments recession intercept $a$ appears to vary throughout the year, in response to catchment-scale water storage in conjunction with spatial heterogeneity (Shaw and Riha, 2012; Shaw et al., 2013; Lyon et al., 2015). Seasonal deviations from the wintertime recession curve have been used to measure catchment scale evapotranspiration (Szilagyi et al., 2007).

Relatively new developments are to interpret changes in recession parameters in terms of changes in the underlying controls or drivers. Brutsaert $(2008,2010)$ used time series of annual low-flow discharge for catchments in Illinois and the eastern USA to detect a (mostly increasing) trend in groundwater storage within the upstream riparian aquifers. Lyon et al. (2009) applied similar methods, combined with the linearized Boussinesq equation, to a streamflow record of a subarctic catchment to determine temporal trends in $a$, attributed to a trend in aquifer thickness $D$, taken as a proxy of effective depth to permafrost. The resulting permafrost thawing rate was in agreement with direct observations. Similar results were obtained for the Yukon catchment (Lyon and Destouni, 2010) and the Lena Basin (Brutsaert and Hiyama, 2012).

\section{Material and methods}

This study is situated in Sweden, which serves as an example country for boreal landscapes. The extensive and longterm river discharge monitoring network in Sweden, in combination with strong gradients in climate (mean annual temperature ranging from $<0{ }^{\circ} \mathrm{C}$ in the north to $8{ }^{\circ} \mathrm{C}$ in the south), land cover and human habitation (Fig. 1; see also van der Velde et al. (2013a), their Fig. 1), make this country ideal for studying effects of co-evolutionary processes on the hydrological cycle, as previously demonstrated by studies of Destouni et al. (2013), van der Velde et al. (2013a, b), and Lyon et al. (2009).

\subsection{Data}

The Swedish river discharge monitoring network (Swedish Meteorological and Hydrological Institute, SMHI, vattenwebb.smhi.se) monitors daily discharge of 316 rivers, all of which were considered for the present study. Data extent varied per catchment. Starting years varied between 1850 and 1998 (median 1947) and ending years varied between 1980 and 2011 (median 2011 as well), allowing us to evaluate human effects on river discharge for at least 50 years. Data coverage is good, with only $3 \%$ of daily values flagged as "missing" by SMHI. The catchment area of each discharge station was reconstructed via delineation from a $30 \mathrm{~m}$ resolution digital elevation model. Catchments where the reported area by SMHI and reconstructed area matched within 5\% were retained for further analysis (289 catchments, ranging from 3 to $33000 \mathrm{~km}^{2}$ with a median size of $390 \mathrm{~km}^{2}$ ). Climate (luftwebb.smhi.se), land cover (Corine land use data), elevation (Landmateriet), and soil characteristics for each of these catchment are adopted from van der Velde et al. (2013a).

\subsection{Recession analysis}

Continuous streamflow records were analysed to identify individual recession events. Subsequently, Eq. (2) was fitted to the resulting multiple short-duration recession hydrographs summarized in a $-\mathrm{d} Q / \mathrm{d} t$ vs. $Q$ data cloud.

Because of sometimes strong anthropogenic controls of streamflow (i.e. dams and other hydraulic constructions) reliable recession analysis is not always possible for every location and/or time period. Often, but certainly not always, these cases can be recognized visually from inspection of the hydrographs. In order to minimize the amount of subjective screening, a methodology based on uncertainty analysis was used to select temporal windows that are used for final data analysis.

\subsubsection{Recession extraction}

Several methodologies to extract individual recession events from continuous streamflow records have been proposed, mainly differing in their approach to distinguish between intrastorm (quick flow) recession and true interstorm (base flow) recession flow. Proposed solutions to overcome these issues include smoothing of hydrographs (Vogel and Kroll, 1992; Tague and Grant, 2004), skipping over initial phases of recession (Brutsaert and Nieber, 1977; Vogel and Kroll, 1992), final stages (Brutsaert, 2008) and large drops in discharge (Vogel and Kroll, 1992). Stoelzle et al. (2013) compared three recession extraction methods (Brutsaert, 2008; Vogel and Kroll, 1992; Kirchner, 2009) in conjunction with their corresponding parameterization methods (see below), and all possible combinations. It was found that estimates for recession characteristics like recession time varied over 

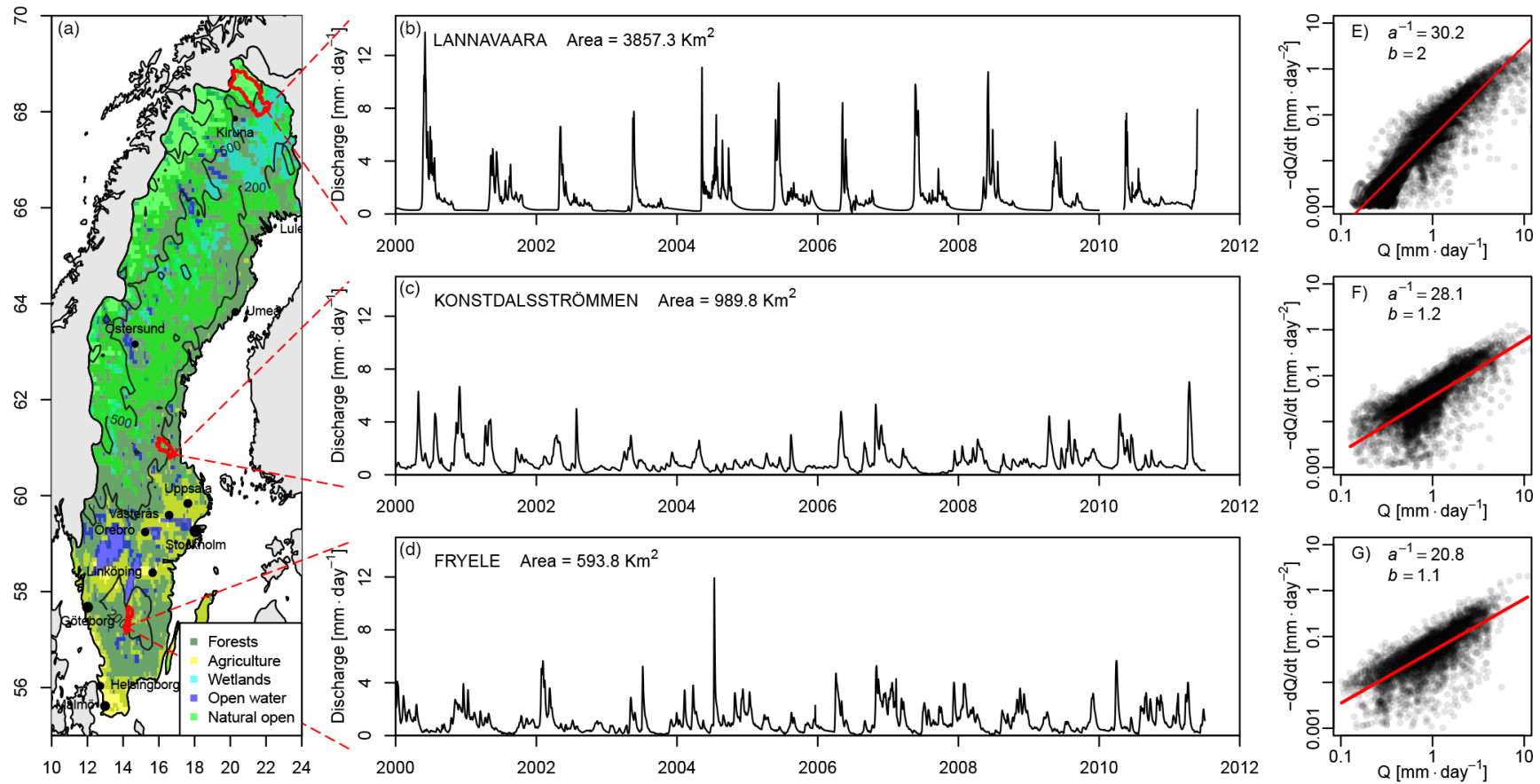

Figure 1. Land cover, elevation, and major cities in Sweden, with three catchments highlighted. For each of these catchments the hydrographs $(\mathbf{b}, \mathbf{c}$, and $\mathbf{d})$ and the recession analyses $(\mathbf{e}, \mathbf{f}$, and $\mathbf{g})$ are shown.

1-2 orders of magnitude. Their results also suggest that the most robust (i.e. least variable) estimate of $b$ is yielded by the Vogel and Kroll (1992) extraction method (see Appendix A).

We broke up individual streamflow records in subsets of maximum 5 years long, always starting at rounded dates such as 1 January of 1960, 1965, 1970, etc. For each of these subsets, recession periods were extracted using the following constraints (modified from Vogel and Kroll, 1992): a recession period is a period in which both discharge and smoothed discharge (3-day moving average) are decreasing. Steady base-flow tails were removed by clipping off against a threshold (10\% of the range minimum-median streamflow). Also, data points corresponding to extremely low streamflow $\left(Q<0.1 \mathrm{mmday}^{-1}\right)$ or recession $(-\mathrm{d} Q / \mathrm{d} t<$ $0.1 \mathrm{~mm} \mathrm{day}^{-2}$ ) were excluded. All recession periods of at least 5 days were retained.

\subsubsection{Fitting parameters}

In their original development of the method, Brutsaert and Nieber (1977) noted that evaporation during recession flow leads to higher values of $-\mathrm{d} Q / \mathrm{d} t$ for a given value of $Q$, and proposed to fit Eq. (2) to the lower envelope of the $Q$ vs. $-\mathrm{d} Q / \mathrm{d} t$ data cloud, which in their application is fitted by eye. Brutsaert and Hiyama (2012) further add that the use of a lower envelope yields, for a given $-\mathrm{d} Q / \mathrm{d} t$, the maximum value of $Q$, ensuring that the entire catchment is contributing.

Later applications recognized the possibility of data errors and allowed 5\% (Brutsaert, 2008) to 10\% (Zecharias and
Brutsaert, 1988) of the data points to be below the lower envelope, and use (non-)linear regression as a more objective alternative to the fit-by-eye envelope approach (Zecharias and Brutsaert, 1988; Vogel and Kroll, 1992; Parlange et al., 2001; Tague and Grant, 2004; Lyon et al., 2009; Lyon and Destouni, 2010).

For larger catchments in hillslope terrain, Brutsaert (2005) suggested that the power law (Eq. 2) should be fitted through the entire data cloud (i.e. not using a lower envelope), because heterogeneity in the subsoil likely overshadows the effect of evapotranspiration.

Kirchner (2009) used an alternative approach to noise and errors in discharge data by binning together individual hourly data points in ranges ("bins") of $Q$, and computing average $Q$ and $\mathrm{d} Q / \mathrm{d} t$ for each bin. Lyon et al. (2009) used this approach to validate their method (non-linear fitting of Eq. 2) while Krakauer and Temimi (2011) use it to analyse $Q$-dependent recession behaviour.

Again looking at the results of a methodological comparison (Stoelzle et al., 2013; see also Appendix A), it is suggested that the most robust estimate of recession parameters is yielded by linear regression. Based on this interpretation, and above arguments, we also chose to use linear regression, rather than a lower envelope or binning.

Therefore, each 5-year time series resulted in a set of $Q$ vs. $-\mathrm{d} Q / \mathrm{d} t$ recession data points through which Eq. (2) was fitted. We followed common procedure by not fitting the non- 
linear model but instead fitting the log-transformed model

$\log (-\mathrm{d} Q / \mathrm{d} t)=\log (a)+b \log (Q)$

using simple linear regression with ordinary least squares to obtain estimates of parameters $a$ and $b$.

\subsubsection{Screening}

As outlined above, suitability of streamflow data for recession analysis varies with time and space. An additional screening step is used to distinguish between "informative" hydrographs, yielding useful estimates of $a$ and $b$, and "degenerated" hydrographs, yielding unreliable estimates of $a$ and $b$. We distinguished between these cases on the basis of the uncertainty in the regression process. Alternative methods exist to potentially recover degenerated hydrographs (e.g. Rupp and Selker, 2006a) but, given the number of catchments and the daily resolution of the data available, we opt for this screening approach.

A common way of summarizing the fit of regression models is based on the computed coefficient of determination, $R^{2}$; however, we regard this approach as unsuitable because of the dependence of $R^{2}$ on the regression slope $b$ (a slope $b=0$ always corresponds to a $R^{2}$ of 0 , even if the fit is perfect).

Instead, we used the uncertainty $U$ in the estimation of $b$, as quantified by the $95 \%$ confidence interval of $b$ (Helsel and Hirsch, 2002). Based on the highly skewed and long-tailed distribution of $U$ per 5-year period, $U_{5}$, a value of $U_{5}=0.25$ appeared, based on visual inspection of the data cloud and the fitted line, to be an appropriate threshold between the suitable and unsuitable data for further analysis.

A second iteration of screening was performed by gathering, per catchment, all recession data for accepted 5-year periods (i.e. $U_{5}<0.25$ ) and fitting an overall power-law model, Eq. (2). Again, for every catchment the associated uncertainty in $b$ over the whole time series, $U_{*}$, was computed. The distribution of $U_{*}$ was again skewed and long tailed, suggesting a threshold of $U_{*}=0.1$.

In summary, only 5-year intervals with $U_{5}<0.25$ for catchments with $U_{*}<0.1$ are retained. This resulted in a reduction of the original 316 catchments to 220 catchments, for which static (overall) $a$ and $b$ are estimated (see Fig. 1 for examples). The second screening iteration did not result in the erroneous exclusion of catchments with strong changes in recession parameters.

\subsection{Trend analysis}

The occurrence of trends in Brutsaert-Nieber parameters $a$ and $b$ were analysed by computing $a$ and $b$ for all accepted $\left(U_{5}<0.25\right)$ non-overlapping 5-year intervals, and performing a linear trend analysis, using a rather loose $p=0.1$ as a threshold for significance of trends in either $a$ or $b$. Only those catchments that had at least $50 \%$ accepted 5-year inter- val coverage since 1960 were considered. This was the case for 141 out of 220 post-screening catchments.

\subsection{Attribution to catchment properties and external forcing}

Many of the catchment characteristics are highly correlated. For example the fraction of agriculture is correlated to the fraction of clay inside the catchments for these Swedish catchments. These correlations are partly the result of coevolution of soil, vegetation, atmosphere, and humans (for example, humans prefer agriculture on fertile clay soils) and prevent unique identification of the controls on river discharge recession via correlating the catchment discharge recession parameters to other catchment characteristics. To account for this non-uniqueness, we applied an ensemble regression approach to unravel the landscape, climate, and anthropogenic controls on river discharge recession. This setup consists of three steps. First, we created a large ensemble of unique multiple regression models that all relate the empirical recession parameters $a$ and $b$ to catchment characteristics (details are given in Appendix B). Second, the entire ensemble of multiple regression models was used to regionalize parameters $a$ and $b$ over the entire Swedish land mass on a $10 \mathrm{~km} \times 10 \mathrm{~km}$ grid revealing their regional patterns and uncertainty (van der Velde et al., 2013a). Third, we related these regional patterns back to patterns in catchment characteristics and changes thereof (if available), linking observed trends in river discharge recession to potential drivers.

\section{Results}

\subsection{Recession analysis}

\subsubsection{Characteristic parameter values}

For all catchments, values for Brutsaert-Nieber coefficient $a$ ranged from 0.012 to 0.23 , with $90 \%$ of all $a$ values between 0.018 and 0.13 , and $50 \%$ between 0.029 and 0.067 . Values for exponent $b$ ranged from 0.50 to 2.1, with $90 \%$ of all $b$ values between 0.84 and 1.7 and $50 \%$ between 1.1 and 1.4 (Fig. $2 \mathrm{a}$ and b). For $b \approx 1$, catchments behave like a linear reservoir and 1 / $a$ can be interpreted as a recession timescale. Out of the 220 catchments, 71 have values that are approximately linear ( $b$ ranging from 0.9 to 1.1 ). For these, 1 / $a$ varies between 11 and 66 days (median 28.4 days).

\subsubsection{Trends}

The distribution of estimated trends is approximately normal, with a general tendency of decreasing $a$ and increasing $b$ (Fig. 2c and d). For parameter $a, 82$ out of 141 (60\%) catchments showed a significant decreasing trend, while a significant increasing trend in $b$ was found for 70 out of $141(60 \%)$ catchments. Although increasing $a$ and decreasing $b$ trends 

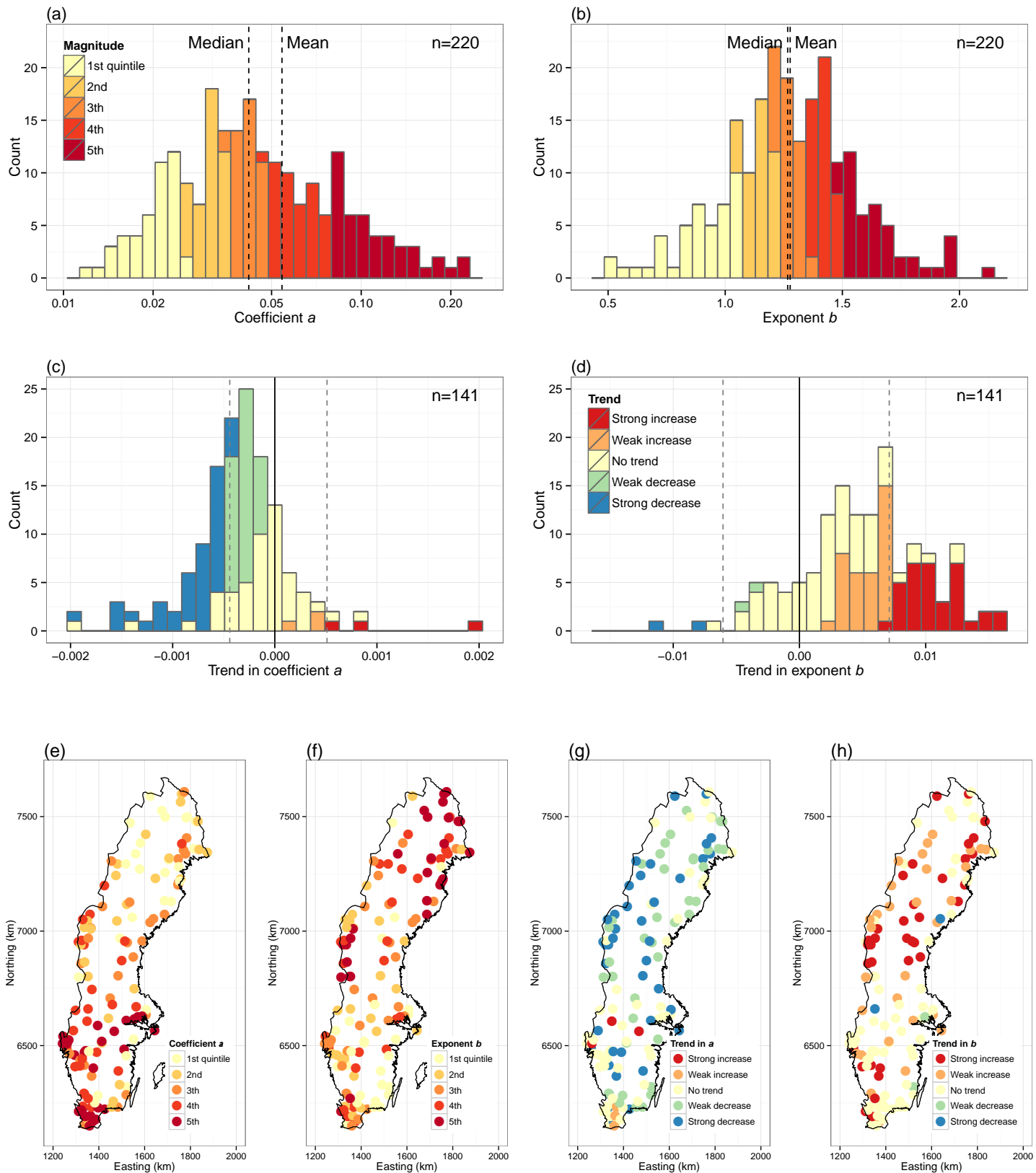

Figure 2. Top row: distributions of long-term average catchment-scale Brutsaert-Nieber parameters $a$ (a), note the log axis, and $b$ (b). Coloured background panels indicate distribution quintiles, used as legends in (e) and (f). Centre row: trends in Brutsaert-Nieber parameters $a$ and $b$ (c and d, respectively) coloured by significance and magnitude class. Trends are identified as significant when $p<0.1$. The threshold between strong and weak increase or decrease is taken to be the median of significant increasing or decreasing trend magnitudes, and is indicated with dashed lines. Bottom row: absolute values (e and $\mathbf{f}$ ) and trends ( $\mathbf{g}$ and $\mathbf{h}$ ) of Brutsaert-Nieber parameters $a$ and $b$. Dots are coloured according to quintiles (absolute values, as in $\mathbf{a}$ and $\mathbf{b}$ ), or significance class (trends, as in $\mathbf{c}$ and $\mathbf{d}$ ).

are found, most of them are not significant at the $p=0.1$ level.

The median significant decreasing trend in $a$ is -0.00044 , which over a period of 50 years suggest a total change in $a$ of -0.022 . For the case of linear reservoir catchments, with a median recession timescale $1 / a$ of 28.4 days, as described above, this means an increase from $\approx 22$ to $\approx 48$ days. The median significant increasing trend in $b$ is 0.0071 , which over 50 years suggest a total change in $b$ of 0.35 , which is almost one-third of the typical range for $b$ of 1 to 2 . Note that these change magnitudes are for those locations where change does occur, i.e. these are not country-scale overall change magnitudes, which would require a different approach to assess. 
Combined these results suggest a progressive change towards slower recession (or increased retention) and increased non-linearity of catchments throughout Sweden during the last 50 years.

\subsubsection{Spatial distribution}

The pattern in the spatial distribution of recession parameters (220 catchments) generally follows a north-south gradient: $a$ values are generally high in southern Sweden and low in northern Sweden. For $b$ this pattern is reversed (Fig. 2e-f). For trends in $a$ and $b$ the picture is less clear (Fig. $2 \mathrm{~g}-\mathrm{h}$ ). The majority of trends in $a$ are either stable (i.e. no significant trend) or decreasing, without a clear spatial pattern. The few catchments with increasing trends are all located in southern Sweden. For $b$, the picture is not completely similar. While southern Sweden is characterized by mostly stable or weak increasing $b$, northern Sweden is mostly weak and strong increasing. The few decreasing trends are scattered across the country.

\subsection{Attribution}

\subsubsection{Spatial explicit correlation}

The results of the attribution, shown in Fig. 3, revealed that Brutsaert-Nieber coefficient $a$ is best predicted from the lake fraction within catchments (open water), catchment area (area), and total annual precipitation (precip.). When the area fraction with slopes exceeding $10 \%$ (\% slope $>10 \%$ ) is added as an additional regression variable, $R^{2}$ for $a$ approaches the maximum value of $\approx 0.8$.

Brutsaert-Nieber exponent $b$ was found to be best explained from open water, the amount of precipitation that falls as snow (psnow), the fractional presence of clay soils (clay), and the average yearly catchment temperature (temp). Maximum $R^{2} \approx 0.7$ is reached when four additional variables are added: the fractional area covered by rocks (rock), slopes exceeding $10 \%$, slopes exceeding $5 \%$, and the fractional coverage of wetlands (wetlands).

It should be noted that many variables are strongly correlated with each other. Since the method used favours unique information carried by variables, typically only one of a set of strongly correlated variables is picked up and gets a high presence. One example is clay (rank 3), which is favoured above agriculture (rank 13).

All explanatory variables can be loosely classified as either terrain (elevation, slope), climate (temperature, precipitation, snow, degree days - DD, temperature seasonality index - TSI, precipitation seasonality index - PSI), land cover/use (open water, wetlands, agriculture, forest, natural open), soil (clay, rock, sand, till, artificial, peat), and other (catchment area). There is no clear ranking of these categories in terms of explanatory power (Kruskal-Wallis test; $p=0.72$ ), the
Table 2. Typical range in recession parameters for various dominant land use types for catchments of $100 \mathrm{~km}^{2}$. Ranges are based on the envelopes of the $80 \%$ probability region in Fig. 4 .

\begin{tabular}{lcc}
\hline Land use type & $1 / a$ & $b$ \\
\hline Agriculture & $7-17$ & $1.1-1.5$ \\
Wetland & $9-22$ & $1.5-1.9$ \\
Natural open & $5-15$ & $1.4-1.8$ \\
Forest & $10-27$ & $1.0-1.5$ \\
Open water & $27-45$ & $0.7-1.3$ \\
\hline
\end{tabular}

largest difference being climate ranking slightly above terrain (Wilcoxon test; $p=0.25$ ).

Regionalization of $1 / a$ and $b$ (Fig. 3) yielded only locally varying patterns for $1 / a$, while $b$ also shows a clear northsouth gradient likely related to temperature and/or snow. However, a similar north-south pattern could also arise from the fraction of wetlands (Fig. 1) that follow a similar pattern.

Ensemble predictions for $1 / a$ and $b$ are robust, having a (ensemble) coefficient of variation of mostly $<0.2$. Exceptions are the high north and within some large lakes (where the model assumptions break down).

\subsubsection{Phase-space land use clusters}

Finally, to unravel the controls on the recession parameters, for all the $10 \mathrm{~km} \times 10 \mathrm{~km}$ grid cells of our regionalization maps (Fig. 3), the 1 / $a$ values are plotted against corresponding $b$ values, with trends superimposed. These "phase diagrams" are analysed by highlighting major land cover types, highlighted as $80 \%$ probability contours (Fig. 4). The general pattern is that most $80 \%$ land cover contours lie along a diagonal where $1 / a$ and $b$ are negatively correlated (such that $a$ and $b$ are positively correlated).

It has been found that natural open landscapes have the shortest recession timescale (i.e. drain the fastest) followed by agriculture, wetlands, and forest, and finally open water, which is slowest (Table 2).

At the same time, open water has the lowest range in Brutsaert-Nieber exponent $b$, followed by forest, agriculture, natural open and finally wetlands, which behave in the most non-linear way (Table 2).

Trends are all in the same direction of $1 / a$ and $b$, i.e. both increasing.

\section{Discussion}

Overall, our results regarding ranges of Brutsaert-Nieber parameters $a$ and $b$ compare well with values reported in the literature. Here, timescale 1 / $a$ varied mostly between 11 and 66 days. This range is slightly low, compared to the typical range of $45 \pm 15$ days as reported by Brutsaert (2008) for large river basins, but their result was obtained using a lower 

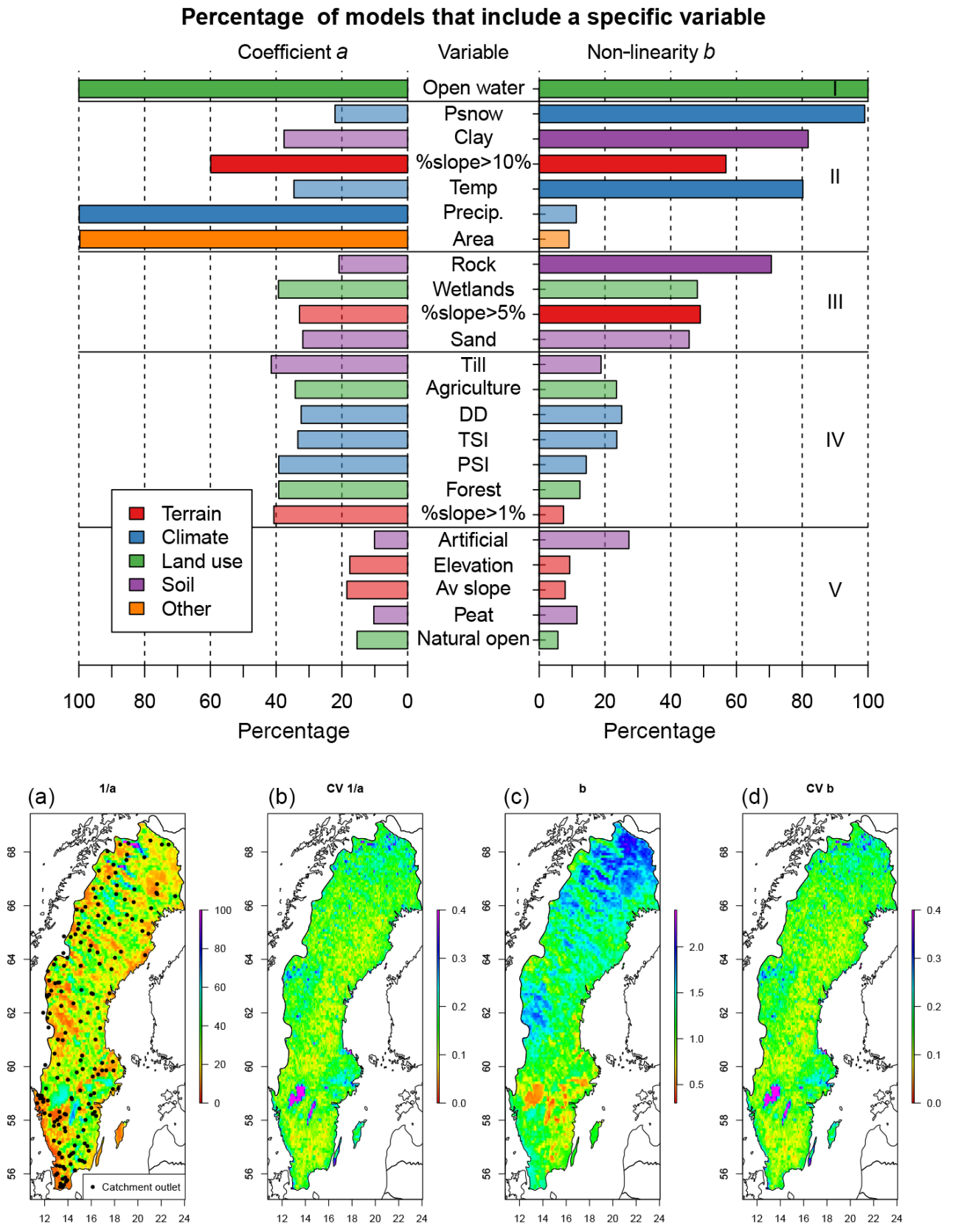

Figure 3. Top panel: explaining variables for Brutsaert-Nieber coefficient $a$ (left) and exponent $b$ (right), ordered by combined presence in regression models. Bars are coloured by category (terrain, climate, soil, land use, other). Saturated bars indicate those variables that are required to approach maximum cumulative $R^{2}(\approx 0.8$ for $a$ and $\approx 0.7$ for $b)$. Bottom panels: spatial extrapolation of the Brutsaert-Nieber parameters, obtained by an ensemble of 1000 regression models and a uniform catchment area of $100 \mathrm{~km}^{2}$. Panels depict (a) ensemble mean of $1 / a$, (b) coefficient of variation of $1 / a,(\mathbf{c})$ ensemble mean of $b,(\mathbf{d})$ coefficient of variation of $b$.

envelope method, which by design results in lower $a$ and hence higher $1 / a$. Also, our result of exponent $b$ varying mostly in the range 1.1-1.4 corresponds well with ranges for $b$ reported in earlier studies (Wittenberg, 1999; Troch et al., 2013a).

\subsection{Mechanistic interpretation of recession parameters}

Based on theoretical arguments (Sect. 1.1) and previous applications of the Brutsaert-Nieber framework (Sect. 1.2), many more detailed interpretations of the results can be made, each linked to individual natural or anthropogenic controls. 

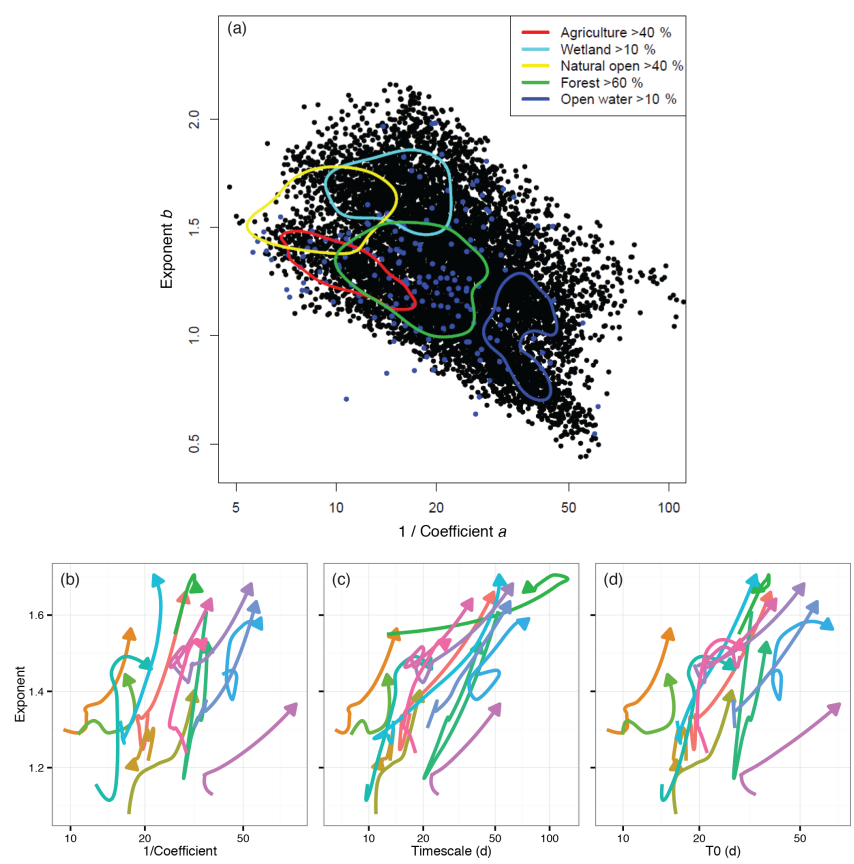

Figure 4. (a) Land cover controls on Brutsaert-Nieber recession parameters $a$ and $b$. The contours represent the $80 \%$ probability region for $10 \mathrm{~km}$ grid cells with a dominant land cover. Black dots represent the normalized $10 \mathrm{~km}$ grid cells; blue dots the original catchments. (b) Trends in $1 / a$ and $b$ for the period 1950-2000, for a representative subset of catchments. Values are computed per catchment and year, using moving and overlapping 5-year time windows and smoothed in the time domain with a LOESS smoother. Colours identify individual catchments. (c) Similar, but using the timescale $T$ (Eq. (5), using the 95th percentile of $Q$ as $Q_{0}$ ). (d) Similar, but using the timescale $T_{0}$ (Eq. 6).

\subsubsection{Landscape}

Different dominant land use types (agriculture, forest, natural open, wetlands, and open water) occupy distinct regions in a $b$ vs. $1 / a$ diagram (Fig. 4). This can be interpreted with the help of the available set of physical processes operating in various landscapes (Table 1 ).

The lowest $b$ values $(0.7-1.3)$ are found for open water. The clustering around $b=1$ suggests that for these catchments the linear-reservoir type behaviour might be influenced by the effects of open-water-related hydraulics ( $b=1-$ 1.3 for open-channel flow; $b=1.33$ for weirs), rather than hillslope subsurface flow dynamics $(b=1.5-2)$. The corresponding $1 / a$ values are the largest of all land use types suggesting the longest recession timescales, which is consistent with the large volumes stored in surface water reservoirs.

Forests have $b$ values roughly ranging from 1.0 to 1.5 , which is consistent with classic physical models as linear reservoirs $(b=1)$ or flat-lying aquifers in homogeneous substrate $(b=1.5) .1 / a$ values are intermediate, meaning faster drainage than for open-water-dominated catchments, but slower than for agricultural and natural open areas.

Agricultural areas have a narrower range in $b$ values, roughly between 1.1 and 1.5 , again consistent with flat homogeneous aquifers or linear reservoirs. Values for $1 / a$ ranging from 7 to 17 day are among the lowest values compared to other land use types. A possible explanation for this is the presence of artificial drainage, which is commonly applied in Sweden for fast drainage of excess water after rain storms (e.g. Ulén and Jakobsson, 2005). From Table 1 it follows that a high drainage density and a high conductivity is related to low values for $1 / a$.

Natural open areas have similar relatively short recession timescales as agricultural areas, but with a larger range, and higher $b$ values, 1.4 to 1.8 . High $b$ values are characteristic for soils with saturated hydraulic conductivity decreasing with depth: exponential profiles result in $b=2$ (Troch et al., 1993) while power-law profiles result in $b$ ranging from 1 to 2 (Rupp and Selker, 2006b). These type of soils are commonly found in upland regions with in situ weathered soils.

Wetlands have slightly higher $b$ values (1.5-1.9) and smaller $a$ values (slightly higher $1 / a$ values), suggesting slightly more non-linear behaviour and slower drainage than natural open areas. This is consistent with the water-retention effect of wetlands shown earlier for Sweden (Lyon et al., 2012). The range of $b$ values is consistent with both channelflow hydraulics and wetland peat soils where, due to compaction, hydraulic conductivity decreases with depth, causing $b$ up to 2 .

Interestingly, the $80 \%$ contour lines for open water and wetlands do not overlap at all, suggesting that these land cover classes are governed by different, mutually exclusive, physical mechanisms, e.g. "constant" low-resistance flow in channel networks vs. high-resistance overland flow in wetlands, which can be seen as an surface extension of the vertical soil conductivity profile.

The strong association of exponent $b$ with the explanatory variable clay is in agreement with other studies that, although on a smaller scale, found $b$ related to the percentage of highly conductive soils (Tague and Grant, 2004; McMillan et al., 2014).

\subsubsection{Precipitation}

Using annual precipitation data for 270 catchments, it is clear that precipitation has increased: averaged over all catchments there has been an increase of $5.9 \%$ since 1960 ( $4 \mathrm{~mm} \mathrm{yr}^{-1} \mathrm{yr}^{-1} p \ll 0.01$ ). On the catchment scale, 173 out of 270 catchments $(64 \%)$ have experienced a significantly $(p<0.05)$ increased annual precipitation, while for the remaining 97 catchments (36\%) no significant trend has been detected. Zooming in on seasonal timescales, this picture changes: for the winter months, only 22 catchments $(8 \%)$ show a significant increasing trend, while for the summer months this is 158 catchments (59\%). The increase in annual 
precipitation has thus predominantly been due to increased summer precipitation.

Precipitation rate $(P)$ has a strong effect on hydrological statistics such as mean or peak discharge, but it is not present in any of the $a / b$ formulae (Table 1 ). This by itself suggest that changes in precipitation will cause a shift along the power-law curve (Eq. 2) rather than a transformation of the curve itself. It is therefore not expected that recession parameters are correlated with the annual precipitation rate. Although the annual precipitation rate was found to be an important explanatory variable for recession intercept $a$, this result is mainly for precipitation in conjunction with other variables. The correlation coefficient for annual precipitation as a single explanatory variable is close to 0 , confirming the expected independency.

Similarly, changes in recession parameters are not expected to correlate with changes in the annual precipitation rate. Indeed, no significant correlations $\left(R^{2}>0.1\right)$ have been detected between trends in (seasonal) precipitation and trends in recession parameters $a$ and $b$, suggesting that trends in recession behaviour of catchments are independent of precipitation.

On the other hand, a higher precipitation rate might lead, ceteris paribus, to increased storage and generally higher groundwater levels. Depending on the vertical hydraulic conductivity profile, and location of macropores, this may trigger faster flow paths and thus an increased total transmissivity. For linear reservoirs $(b=1)$ or flat Boussinesq aquifers $(b=1.5)$, there may be, through increased effective $k$, an effect on $a$ (Table 1), while for TOPMODEL-type non-linear reservoirs $(b=2)$ any effects might be built-in already in the associated recession model, and therefore not be visible. If such a precipitation-storage-conductivity mechanism would be operative, one would expect a relationship between the annual precipitation rate and recession parameter $a$, which is stronger for lower values of $b$. However, since the correlation between $a$ and precipitation as a single explanatory variable is close to 0 , there appears to be no evidence for such a mechanism, either because this hypothesis is false, or because it is linked to event-scale precipitation, which was not analysed here.

A similar mechanism would link a high storm precipitation rate to occurrences of overland flow and other thresholdexceeding mechanisms, suggesting a different drainage behaviour under wet (i.e. high-flow) conditions than under normal conditions. Although overland flow and similar mechanisms are beyond the Boussinesq interpretation of BrutsaertNieber diagrams, they should still be visible within these diagrams, if their recession behaviour would be markedly different from that of Boussinesq recession. However, no compelling evidence has been found that recession behaviour, as observed, cannot be captured within a single power-law relationship. Furthermore, the trends of increasing exponent $b$ and decreasing $a$ suggest a stronger dichotomy between a wet-condition recession rate and a dry-condition recession rate, i.e. the range in $-\mathrm{d} Q / \mathrm{d} t$ increases.

On the long timescale, an increased precipitation rate may result in an increased drainage density, due to feedbacks between hydrological regime and geomorphological processes (e.g. Tucker and Bras, 1998; Bogaart and Troch, 2006). The resulting increased total stream length $L$ may be associated with higher values for $a$ (Table 1). This suggests that highprecipitation landscapes have higher $a$ values and similar $b$ values, compared to otherwise similar low-precipitation landscapes. Again, $a$ and annual precipitation were found to be uncorrelated. Unfortunately, reliable direct data on drainage density was not available, leaving this analysis of a potential geomorphological feedback unresolved.

\subsubsection{Temperature}

For temperature, a similar picture arises as for precipitation: $96 \%$ of all catchments show a warming trend on the annual timescale, and none show a cooling trend (see also Saaltink et al., 2014). For the seasonal timescales, these percentages are $23 \%$ (winter) and $73 \%$ (summer). Rising temperatures have thus been mainly due to warmer summers.

Again, trends in (seasonal) temperature (where significant) have been compared to trends in recession parameters $a$ and $b$. In none of the cases did we find a correlation coefficient $R^{2}>0.1$, which suggests that trends in recession behaviour of catchments are independent of temperature.

\subsubsection{Streamflow}

Trends in recession parameters $a, b$ and $T$ have also been compared to trends in streamflow magnitude parameters. These parameters include indicators for base flow, $\left(Q_{90}\right.$, specific discharge that is exceeded $90 \%$ of time), mean conditions $\left(Q_{50}\right)$, and peak flow $\left(Q_{10}\right)$. As with climate. trends in these streamflow statistics (if any) where not correlated to trends in recession parameters (all $R^{2}<0.1$ ). This suggests that trends in recession behaviour capture unique information not present in traditional flow statistics.

\subsubsection{Evapotranspiration}

For evapotranspiration $(E)$, multiple mechanisms can be considered. First, on the annual timescale, increased $E$ may, ceteris paribus, lead to desiccation of the landscape and an increase of available water storage capacity within the soil. This increased buffer capacity results in less and smaller discharge peaks. Because no effect of $a$ and $b$ as such is expected, one expects that changes in annual $E$ result in a shift along the Brutsaert-Nieber curve, which itself remains unaltered. This is the same mechanism as outlined above for precipitation, suggesting that there is no relationship between annual $E$ and the Brutsaert-Nieber recession parameters. Average actual evapotranspiration rate $E$ has been computed for 138 catchments where both precipitation data and suf- 
ficient streamflow data were available to determine the water balance. $E$ (as fraction of annual precipitation), $E / P$ and recession coefficient $a$ are weakly correlated $\left(R^{2}=0.11\right.$; $p<0.001)$ but $E / P$ appeared to be negatively correlated to recession exponent $b\left(R^{2}=0.27\right)$. This is consistent with the spatial pattern of low $b$ values and high $E$ rates in southern Sweden, as found by van der Velde et al. (2013a), who linked these high $E$ rates to the intensive agriculture and many lakes found there. Thus, recession behaviour is more strongly associated with evapotranspiration than with precipitation.

Note that this association between patterns in $E, a$, and $b$ are not necessarily indicative of a direct causal relationship, but may rather be the result of underlying geographic gradients (climate, soils, land use) that are partly contingent (e.g., geology) and partly interrelated (e.g., land use)

As with precipitation, changes in annual $E$ were not expected to be linked to trends in Brutsaert-Nieber recession parameters. Unfortunately, there was not enough data available in this study to warrant a comparison between catchment-scale changes in $E$ rate and recession parameters. However, van der Velde et al. (2013a) found that on average, precipitation trends are $\approx 2.9 \mathrm{~mm} \mathrm{yr}^{-2}\left(0.4 \% \mathrm{yr}^{-1}\right)$ while $E$ trends are $\approx 1.6 \mathrm{~mm} \mathrm{yr}^{-2}\left(0.5 \% \mathrm{yr}^{-1}\right)$, resulting in a fairly stable ratio $E / P \approx 0.4$ (increasing with only $0.1 \% \mathrm{yr}^{-1}$ ). Analysing spatial patterns of change in $E / P$, van der Velde et al. (2013b) found increases in this ratio mostly associated with agricultural land use in southern Sweden (due to increased water use efficiency), where $b$ values are relatively low (due to low relief and homogeneous soils). Looking at these results on their own merit ( $b$ negatively correlated with $E / P, E / P$ either increasing (southern Sweden) or stable), one may reason that the effect of $E / P$ on $b$ should be a stable or decreasing trend in $b$, which is inconsistent with the main finding of increasing $b$. However, a more detailed look into the relation between trends in recession parameters vs. absolute values (Appendix D) shows that the increasing trends in $b$ are mainly associated with those catchments that already have a high value of $b$. Since the slight increase in $E / P$ is mainly found in the south, where $b$ is generally low, this more detailed look forces one to conclude that the slightly increased $E / P$ (associated with low $b$ ) is not in direct contradiction with increased $b$ (associated with high $b$ ). Thus, no evidence has been found that trends in $E$ are correlated to trends in recession parameters.

Originally, Brutsaert and Nieber (1977) reasoned that, when similar streamflow events are compared (i.e. similar $Q)$, those events that occur under increased levels of $E$ suffer from increased loss of water, and hence are characterized by a stronger recession or higher $-\mathrm{d} Q / \mathrm{d} t$. Therefore, their data analysis method used only the lower envelope of the $-\mathrm{d} Q / \mathrm{d} t$ vs. $Q$ cloud. As explained in Sect. 2.2, we follow Brutsaert (2005) and fit Eq. (2) through the whole data cloud. This way, stronger/increased (decreased) $E$ would result in an upward (downward) curve of Eq. (2), suggesting that $E$ is positively correlated with recession parameter $a$. Indeed, as explained above, correlation between $E / P$ and $a$ is very weak but significant $\left(R^{2}=0.11 ; p<0.001\right)$.

\subsubsection{Land use}

Land use change comes in many forms, which can be clustered on functional terms. A change in vegetation cover has mainly an effect on (potential) $E$, discussed above. Land management from a hydrological context can be described in terms of artificial drainage. Several (competing) mechanisms can be thought of, each focussing on either $a$ or $b$.

First, artificial drainage in the form of tile drainage or an extended network of shallow ditches can be expected to have a positive effect on effective conductivity $k$, while ditches artificially extend the drainage network $L$. Table 1 states that for flat-lying Boussinesq aquifers (for which $b=3 / 2$ ), $a$ is proportional to $k^{1 / 2}$ and $L$. Although such closed-form relations between $a$ and $L$ are not known to us for other cases, we do expect that artificial drainage leads to higher values for $a$. Because no direct data on drainage extent was available, agricultural land use was used as a proxy. Indeed, agriculture has the shortest recession timescale, i.e. highest values of $a$ (Fig. 4).

On the other hand, artificial drainage leads (by design) to a lower groundwater level, and hence to a more pronounced unsaturated zone. For shallow groundwater levels, drainable porosity (specific yield) $f$ is strongly dependent on groundwater depth: $f=0$ when groundwater is at the soil surface, and increases with groundwater depth until a soil-dependent constant value is reached. According to Table 1, using the equations for Boussinesq aquifers, $a$ is proportional to $1 / f$. If this mechanism were to be dominant, artificial drainage should lead to smaller values for $a$. Because, as discussed above, agriculture is associated with higher values of $a$, this mechanism seems to be small or absent.

Agricultural land use is commonly associated with homogenized soils. In general, values for $b$ are related to the vertical profile in soil hydraulic conductivity (Table 1). For flat-lying aquifers, $b=1.5$ for homogeneous soils (uniform $k$ profile) but when hydraulic conductivity increases with depth according to a power-law $b$ may increase to 2 . For sloping aquifers a similar patterns arises, although with a wider range in $b: b=0$ for steeply sloping aquifers with uniform $k$ to $b=2$ for both a power-law and an exponential decreasing conductivity profile. Therefore, agricultural catchments are expected to have values for $b$ near their lower limit. As shown in Fig. 4, the $80 \%$ contour for agriculture occupies intermediate values for $b$, when considering the total range of $b$ values. On the other hand, for fixed values of $a$ (or $1 / a$, as depicted) it occupies low values of $b$ (i.e. the agriculture contour is located near the lower edge of the $-\mathrm{d} Q / \mathrm{d} t$ vs. $Q$ data cloud). So indeed agricultural catchments have relatively low $b$ values. 
For forestry, the same reasoning can be reversed: although Swedish forests are intensively managed (ditches and remnants thereof are often present), the absence of annual soil cultivation can be expected to result in rehabilitation of natural soil profiles, where conductivity usually decreases with depth (Harr, 1977; Bonell, 1993; Bishop et al., 2004). An exponential conductivity profile is commonly assumed in many hillslope hydrological studies (Beven, 1997). Therefore, (re)forested catchments are expected to have values for $b$ approaching their upper limit. Using the same line of reasoning, we note that the $80 \%$ contour for forest (Fig. 4) is characterized by intermediate values for $b$ (in absolute terms) and low-to-intermediate values when considering typical values for $a$. However, observed trends all move towards higher $b$ values, as expected.

It should be noted that above mechanisms focus on the upper $\approx 1 \mathrm{~m}$, which is commonly unsaturated. Yet, this is the zone that is most relevant for streamflow recessions because it represents the zone between storm and inter-storm groundwater levels.

\subsection{Functional interpretation of trends in recession parameters}

A different view of the temporal trends in Brutsaert-Nieber parameters $a$ and $b$ is yielded by plotting trends in these parameters as phase diagrams (Fig. 4b). As can be seen, most catchments migrate from smaller $(1 / a, b)$ towards larger $(1 / a, b)$. Given the similar pattern in the plots of $(T, b$; Fig. $4 \mathrm{c})$ and ( $T_{0}, b$; Fig. $\left.4 \mathrm{~d}\right)$, we interpret these patterns as a general increase in transit time and non-linearity of the recession process.

The observation that an increasing exponent $b$ is associated with increasing $1 / a$ and hence decreasing $a$ suggests that over time the power law (Eq. 2), as converted to the linear law (Eq. 7), rotates: the steeper the slope $b$, the lower the intercept $\log (a)$. This hypothesis has been tested by plotting power laws for every 5 -year period, and calculating the average point of rotation. It has been found that for the 35 "most complete" catchments in terms of data coverage the rotation point is predominantly (in 20 out of 35 cases) between the median and 75 th percentile of $\log Q$. This suggest that recession has become slower (lower $-\mathrm{d} Q / \mathrm{d} t$ ) for lower discharge, and faster (higher $-\mathrm{d} Q / \mathrm{d} t$ ) for higher discharge, and that the former effect is stronger than the latter effect (see Fig. 5).

In other words, during the last decades, under wet conditions, water has been drained at an increasing rate, while under dry conditions water has been retained longer.

Two possible explanations are due to human impact on the landscape: water management and reforestation.

From the water management perspective, it is often a goal to level out extreme conditions. Too much water as well as too little water is considered harmful for many applications. This is especially true for agriculture: too much water is as-

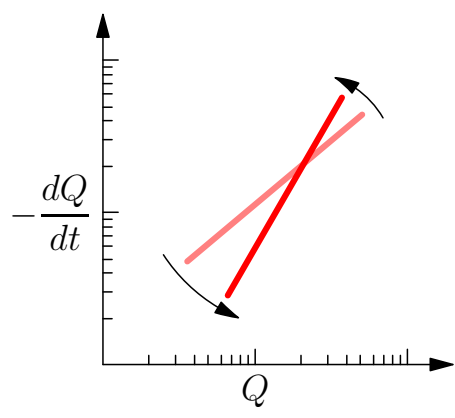

Figure 5. Conceptualization of the general trend in recession behaviour of Swedish catchments: a rotation of the power law $-\mathrm{d} Q / \mathrm{d} t=a Q^{b}$ around intermediate $\log Q$ values.

sociated with flooding, intractable parcels of farm land and oxygen stress for crops. Too little water, on the other hand, is associated mainly with water stress for crops. An optimized agricultural water management is thus focussed on enhanced draining during wet conditions (e.g. by artificial drainage) and enhanced retaining of water under (summer) dry conditions, e.g. by weirs.

As discussed below (Sect. 4.1.6), reforestation is expected to result in a rehabilitation of natural soil profiles, with hydraulic conductivity decreasing with depth. These type of conductivity profiles are associated with relatively high $b$ values (Table 1). At the same time, intensive forestry is also associated with some form of artificial drainage (mainly ditches in Sweden) that have an effect on recession (decreasing $a$ ).

Indeed, many field studies have shown that, for the same soil type, forest have higher near-surface porosity and saturated conductivity (decreasing with depth), compared to pasture or degraded forest, where conductivity profiles are more uniform (Parker and Chartres, 1983; Bormann and Klaassen, 2008; Zimmermann and Elsenbeer, 2008), and that reforestation takes at least 10 years to restore conductivity profiles (Zimmermann et al., 2006; Zimmermann and Elsenbeer, 2008).

In summary, both intensification of water management and reforestation are argued to be consistent with the changes in recession parameters.

\subsection{Similarity of recession analysis with efficiency analysis}

It is interesting to compare the relative positions of the $80 \%$ probability contours in our $a$ vs. $b$ diagram (Fig. 4) with a similar diagram plotting water efficiency $E / P$ vs. energy efficiency $E / E_{\mathrm{pot}}$, the ratio of actual to potential evapotranspiration (van der Velde et al., 2013a, their Fig. 7). For each combination of land use pairs the distance between the contours (as represented by their centroids) can be measured in both diagrams. When comparing these distances (Fig. 6) all but two pairs of distances line up nicely on a diagonal $\left(R^{2}<0.95\right.$, when excluding the two outliers), suggest- 


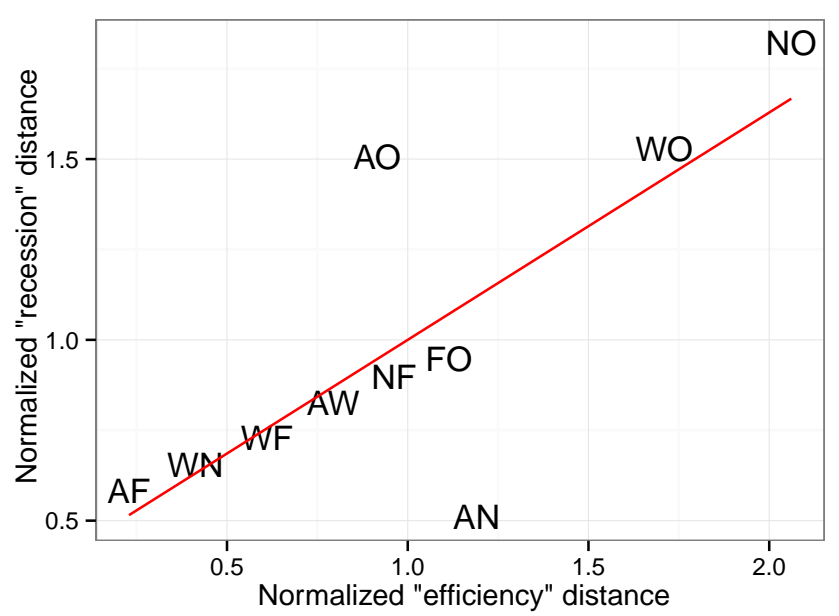

Figure 6. Normalized distance between centroids of $80 \%$ probability contours for land use, as depicted in Fig. 4 ("recession" distance) vs. a similar distance for land use contours in the water efficiency/energy efficiency plot by van der Velde et al. (2013a) (their Fig. 7). Labels identify pairs of land use categories; abbreviations are $\mathrm{A}=$ agriculture, $\mathrm{W}=$ wetland, $\mathrm{N}=$ natural open, $\mathrm{F}=$ forest, $\mathrm{O}=$ open water. Distances are normalized such that the mean distance is 1.0 on each axis. The red line indicates a fitted linear regression model.

ing that when the corresponding land cover types are similar in "recession space" they are also similar in "efficiency space". Likewise, when land cover types are dissimilar in recession space, they are dissimilar in efficiency space. There are two exceptions. The combination agriculture-open water is similar in energy efficiency space, but dissimilar in recession space. For the combination agriculture-natural open this is reversed.

Proximity ( similarity) of agriculture and open water in "efficiency space" can be understood from the fact that both are highly efficient with respect to water and energy. For open water, water limitation is virtually non-existent, and much of available energy is used for the evaporation process. For agriculture, the high efficiencies can be understood from the intensive management and focus on optimal efficiency (i.e. making maximum use of resources). Meanwhile, the large distance (dissimilarity) between these two land cover types in "recession space" can be understood as well: open water is exactly that because it has a long recession timescale; if precipitation cannot be discharged quickly enough, storage increases until surface water bodies emerge. For agricultural areas it is the opposite: water availability is generally plenty, but energy and soil oxygen are potentially limiting factors, which both are improved by rapid (artificial) drainage.

The second combination of land cover types that deviate from the general pattern is that of agriculture and natural open, which are proximal (similar) in recession space, but distal (dissimilar) in efficiency space. As explained by van der Velde et al. (2013a), the large distance in efficiency space is due to their almost complete opposite geographical conditions: natural open landscapes prevail high up in the mountains where temperatures are cold, while agriculture is mainly located in the warmer lowlands. The proximity of these land cover types in recession types is perhaps more of a coincidence. Both types share a very similar fast recession (low $1 / a$ ) but for different reasons: high up in the mountains slopes are steep and soils are young and shallow, both factors promoting fast drainage (Soulsby et al., 2006; Broxton et al., 2009; Tetzlaff et al., 2009), while, as argued before, fast drainage of agricultural areas is mainly due of artificial drainage.

\section{Conclusions}

About 50 years of daily streamflow data for 316 gauging stations in Sweden have been analysed in terms of Brutsaert and Nieber (1977) streamflow recession parameters, and trends therein. Some clear spatial patterns in recession parameters have been found: exponent $b$ generally increases with latitude, causing a more linear $(b \approx 1)$ streamflow response in the south, and a more non-linear $(b>1)$ response in the north. Coefficient $a$, or rather the associated timescale $T=1 / a$, shows a reverse relationship, with slower drainage in the south, and faster drainage in the north. The spatial patterns of both $1 / a$ and $b$ are shown to be clearly linked to catchment properties from the climate-soil-land use complex. Because of strong covariance of these different drivers, no dominant single driver could be identified.

Strong links with land cover have been identified. Each land cover class occupies a well-defined region within $a-b$ phase space, which can be linked to mechanistic explanations based on hydraulic and hydrologic process laws.

Moderate trends in both Brutsaert-Nieber parameters have been found. The general trend is towards slower (decreasing $a$ ) and more non-linear (increasing $b$ ) recession. Although climatic factors are important to explain spatial patterns in recession parameters, trends in recession parameters are not statistically related to trends in either climate (mean annual temperature and/or precipitation) or streamflow magnitude (base flow, peak flow, or average conditions), suggesting that recession parameters carry unique information, as shown earlier in the context of permafrost degradation (Sjöberg et al., 2012).

It is suggested that these trends in recession parameters are consistent with the dominant land use changes in Sweden during the second half of the 20th century, mainly reforestation combined with intensification of the remaining agricultural areas. Both changes are expected to result in faster drainage under wet conditions and longer retention under dry conditions, leading to increased $b$ and decreased $a$. Reasons for this transition differ though: for reforestation it is hypothesised to be due to a restoration of natural depth profiles of soil hydraulic properties, while for agricultural water 
management it is due to management associated with combinations of drainage (pipe drainage, ditches) and retention (weirs).

Many of the patterns and trends in recession parameters results could be attributed to various natural and anthropogenic drivers by invoking physics-based explanations. In other cases their independence to these drivers was confirmed.

Finally, relative positions of most land cover types in $a-$ $b$ "recession" phase space are strongly linked to relative positions in a similar "water and energy efficiency" phasespace plot (van der Velde et al., 2013a), strongly suggesting that land use, catchment-scale water-retention characteristics, and energy partitioning are strongly interrelated, and possibly the result of co-evolution of the landscape. Exceptions in this pattern could be well explained by both natural factors (slow drainage in open-water-dominated landscapes and cold conditions in mountainous natural open landscapes) and anthropogenic effects (yield optimizing crop and water management in agricultural areas).

One possible implication of these results is that models targeted at long-term prediction of streamflow dynamics should take into account the dynamical nature of catchment properties, especially the feedbacks associated with co-evolution of soils, vegetation, and land use. 
Table A1. Analysis of variance of recession indicators with respect to three extraction methods and three fitting methods, using the results of Stoelzle et al. (2013). Numbers between brackets denote ranks.

\begin{tabular}{|c|c|c|c|}
\hline Extraction method & VOG & BRU & KIR \\
\hline $\operatorname{var}(b)$ & 0.272 (second) & 0.327 (third) & 0.133 (first) \\
\hline $\operatorname{var}(y)$ & 0.0202 (first) & 0.0236 (second) & 0.0822 (third) \\
\hline $\operatorname{var}(T)$ & 41.2 (first) & 43.4 (third) & 41.8 (second) \\
\hline Overal rank & first & third & second \\
\hline Fitting method & LE & REG & BIN \\
\hline $\operatorname{var}(b)$ & 0.254 (third) & 0.134 (first) & 0.164 (second) \\
\hline $\operatorname{var}(y)$ & 0.0009 (first) & 0.0119 (second) & 0.0701 (third) \\
\hline $\operatorname{var}(T)$ & 6.8 (third) & 4.3 (first) & 7.8 (second) \\
\hline Overal rank & third & first & second \\
\hline
\end{tabular}

\section{Appendix A: Robustness of recession estimation methods}

As explained in the main text, Stoelzle et al. (2013) compare three different recession extraction and parameterization methods: BRU, after Brutsaert (2008), VOG, after Vogel and Kroll (1992), and KIR, after Kirchner (2009) and three associated parameterization methods: lower envelop fitting (LE; Brutsaert, 2008), linear regression (REG; Vogel and Kroll, 1992), and binning (BIN; Kirchner, 2009). All method combinations were tested, resulting in a total of nine estimates of $a$ and $b$ (their Fig. 1).

For each extraction method, we computed and ranked the variability for the corresponding $b$ estimates. A similar analysis for $a$ would be strongly biased by values of $b$ (because it is an intercept on $\log -\log$ transformed recession data). Therefore, we use a new variable $y$, defined as $-\mathrm{d} Q / \mathrm{d} t$ for a characteristic reference $Q$ (here $1 \mathrm{mmday}^{-1}$ ). Note that $y$ has the same conceptual meaning of $a$. Also, variability for the timescale parameter $T=1 / a$ has been analysed. A similar analysis has been performed for the three fitting models.

From these results (shown in Table A1), we conclude that the least variability in estimation of $b, y$, and $T$ is obtained from the VOG extraction method and the REG fitting method.

\section{Appendix B: Development of linear regression models}

1. a Box-Cox power transformation was applied to each catchment characteristic, and to the river discharge recession parameters $a$ and $b$, to improve normality of the data and importance of extremes in the data set.

2. The transformed parameters $a$ and $b$ were each related to all combinations of the transformed catchment characteristics (from 1 up to 12 explaining variables) using multiple linear regression.
3. The optimal model was selected. This is the model with the lowest Bayesian information criterion (BIC). The $\mathrm{BIC}$ weighs the number of explaining variables against the explained variance.

4. To reduce the sensitivity of the multiple linear regression to outliers in the data set, the catchment that dominates the multiple linear regression in its absolute effect on the sum of explained variances $\left(R^{2}\right)$ for both parameters $a$ and $b$ was removed from the data set. These first four steps were repeated until $5 \%$ of the catchments that dominate the multiple linear regression were removed from the data set.

5. An ensemble of 1000 unique multiple regression models was created by taking 1000 bootstrap samples of the remaining catchments and determining the optimal multiple regression model for each bootstrap sample via steps 1 to 3 of the above-described procedure. The entire ensemble of 1000 multiple linear regression models was then used to represent the mean and uncertainty of parameters $a$ and $b$.

\section{Appendix C: Recession exponent for weirs and open-channel flow}

For a broad-crested weir, $Q \propto L H^{3 / 2}$ (Henderson, 1966; Chaudhry, 2008), where $L$ is the length of the weir, and $H$ is the water depth above the weir. Assuming that effective storage $S$ upstream of the weir is directly proportional to $H$, this results in $Q \propto S^{3 / 2}$. Using $b=2-1 / d$ (Eq. 3; Clark et al., 2009), we obtain $b=4 / 3$.

Recession exponents for open-channel flow are based on an analysis of stream channel networks. Within these networks, channel width $W$, depth $D$, and velocity $V$ are usually related to discharge $Q$ by a power-law relation, the socalled hydraulic geometry relationships $W \propto Q^{b}, D \propto Q^{f}$, and $V \propto Q^{m}$. Because $Q=W D V, b+f+m=1$. Locally, storage $S$ can be expressed as $S \propto W D$ and therefore $S \propto$ $Q^{b+f}$ implying $Q \propto S^{1 /(b+f)}$. Again using $b=2-1 / d$, we obtain $b=2-(b+f)$.

In their classical paper introducing the topic, Leopold and Maddock Jr. (1953) distinguish between at-a-station and downstream hydraulic geometry. Analysing many rivers, they find $b=0.26, f=0.40$, and $m=0.34$ (at-a-station) and $b=0.5, f=0.4$, and $m=0.1$ (downstream), suggesting $b=1.34$ and $b=1.1$, respectively.

A detailed analysis of the New Zealand Ashley and Taieri river basins resulted in $b=0.440$ and $f=0.242$ (Ashley) and $b=0.517$ and $f=0.247$ (Taieri), suggesting BrutsaertNieber $b=1.318$ and $b=1.236$ (Ibbitt, 1997).

For optimal channel networks (Rodríguez-Iturbe et al., 1992), $b=f=0.5$, suggesting $b=1$, but according to Molnar and Ramirez (2002) this is unlikely to occur in nature. 

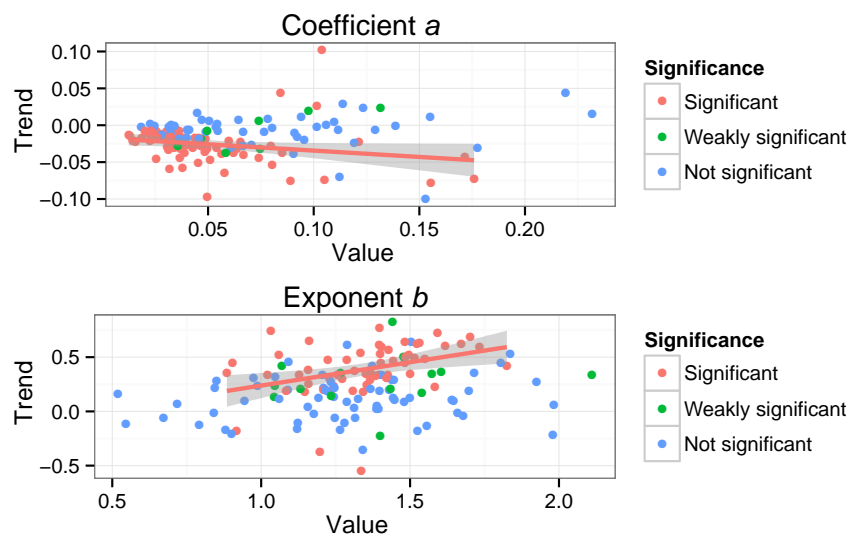

Figure C1. Dependence of trends in recession parameters $a$ and $b$, related to static parameter values. Catchments are classified according to the $p$ value of the trend analysis: significant for $p<0.05$ and weakly significant for $0.05<p<0.1$. Also shown is a fitted linear regression model, along with the corresponding $95 \%$ confidence bands (for significant catchments only).

Above results are based on the assumption that only local storage $S=W D$ is related to discharge. A more landscapescale approach can be obtained by taking total network storage into account.

As Howard (1990) has shown, optimal channel networks can also be created when random walk networks are combined with local drainage along the steepest descent flow paths. For a virtual gridded stream network, generated with this technique, and scaled by total area of the Ashley and Taieri basins, bankfull channel width and depth have been computed for each grid cell, using hydraulic geometry relations for these basins as described above. Now, for every grid cell, total channel storage upstream of that grid cell can be computed and related to discharge (which is assumed to be proportional to drainage area). This resulted in $Q \propto S^{0.7875}$ (Ashley) and $Q \propto S^{0.7561}$ (Taieri) resulting in Brutsaert-Nieber $b=0.73$ and $b=0.68$, respectively.
To what extent Brutsaert-Nieber $b<1$ are physically realistic remains to be seen. As Bogaart et al. (2013) have argued, any process that is unable to dry up completely within finite time (i.e. $Q \downarrow 0$ as $S \downarrow 0$ ) by necessity results in $b \geq 1$.

Summarizing, we conclude that open-channel flow results in Brutsaert-Nieber exponents ranging from 1, when landscape-scale water storage is taken into account, to approximately $1.2-1.3$ when only point-scale storage is taken into account.

\section{Appendix D: Metatrends}

For catchments where a significant trend has been found $(p<0.05)$, trend magnitude is related to parameter value (Fig. C1). For coefficient $a$, this relation is rather weak ( $p=$ $0.047)$, but for exponent $b$ it is significant ( $p=0.0044)$. This means that linear (i.e. $b \approx 1$ ) catchments remained close to linear, but non-linear catchment $(b>1.5)$ became more strongly non-linear. It also clear from this figure that significant trends are mainly found for moderate parameter values. All trends for $b<0.9$ or $b>1.8$ were insignificant. 
Acknowledgements. We thank David Rupp, Ross Woods, Basudev Biswal, Hilary McMillan, John Ding, an anonymous reviewer, and three Wageningen University MSc students for their constructive and thoughtful comments that helped improving this paper.

Edited by: S. Uhlenbrook

\section{References}

Beck, H. E., van Dijk, A. I. J. M., Miralles, D. G., de Jeu, R. A. M., Sampurno Bruijnzeel, L. A., McVicar, T. R., and Schellekens, J.: Global patterns in base flow index and recession based on streamflow observations from 3394 catchments, Water Resour. Res., 49, 7843-7863, doi:10.1002/2013WR013918, 2013.

Beven, K.: TOPMODEL: a critique, Hydrol. Process., 11, 10691085, doi:10.1002/(SICI)1099-1085(199707)11:9<1069::AIDHYP545>3.0.CO;2-O, 1997.

Bishop, K., Seibert, J., Köhler, S., and Laudon, H.: Resolving the Double Paradox of rapidly mobilized old water with highly variable responses in runoff chemistry, Hydrol. Process., 18, 185189, doi:10.1002/hyp.5209, 2004.

Bogaart, P. W. and Troch, P. A.: Curvature distribution within hillslopes and catchments and its effect on the hydrological response, Hydrol. Earth Syst. Sci., 10, 925-936, doi:10.5194/hess10-925-2006, 2006

Bogaart, P. W., Rupp, D. E., Selker, J. S., and van der Velde, Y.: Late-time drainage from a sloping Boussinesq aquifer, Water Resour. Res., 49, 7498-7507, doi:10.1002/2013WR013780, 2013.

Bonell, M.: Progress in the understanding of runoff generation dynamics in forests, J. Hydrol., 150, 217-275, doi:10.1016/00221694(93)90112-M, 1993.

Bormann, H. and Klaassen, K.: Seasonal and land use dependent variability of soil hydraulic and soil hydrological properties of two Northern German soils, Geoderma, 145, 295-302, doi:10.1016/j.geoderma.2008.03.017, 2008.

Brooks, E. S., Boll, J., and McDaniel, P. A.: A hillslope-scale experiment to measure lateral saturated hydraulic conductivity, Water Resour. Res., 40, W04208, doi:10.1029/2003WR002858, 2004.

Broxton, P. D., Troch, P. A., and Lyon, S. W.: On the role of aspect to quantify water transit times in small mountainous catchments, Water Resour. Res., 45, W08427, doi:10.1029/2008WR007438, 2009.

Brutsaert, W.: Hydrology, an Introduction, Cambridge University Press, Cambridge, UK, 605 pp., 2005.

Brutsaert, W.: Long-term groundwater storage trends estimated from streamflow records: climatic perspective, Water Resour. Res., 44, W02409, doi:10.1029/2007WR006518, 2008.

Brutsaert, W.: Annual drought flow and groundwater storage trends in the eastern half of the United States during the past two-third century, Theor. Appl. Climatol., 100, 93-103, doi:10.1007/s00704-009-0180-3, 2010.

Brutsaert, W. and Hiyama, T.: The determination of permafrost thawing trends from long-term streamflow measurements with an application in eastern Siberia, J. Geophys. Res.-Atmos., 117, D22110, doi:10.1029/2012JD018344, 2012.

Brutsaert, W. and Nieber, J. L.: Regionalized drought flow hydrographs from a mature glaciated plateau, Water Resour. Res., 13, 637-643, doi:10.1029/WR013i003p00637, 1977.
Chaudhry, M. H.: Open-Channel Flow, 2nd Edn., Springer Science+Bussiness Media: New York, 523 pp., doi:10.1007/978-0387-68648-6, 2008.

Clark, M. P., Rupp, D. E., Woods, R. A., Tromp-van Meerveld, H. J., Peters, N. E., and Freer, J. E.: Consistency between hydrological models and field observations: linking processes at the hillslope scale to hydrological responses at the watershed scale, Hydrol. Process., 23, 311-319, doi:10.1002/hyp.7154, 2009.

Destouni, G., Jaramillo, F., and Prieto, C.: Hydroclimatic shifts driven by human water use for food and energy production, Nature Clim. Change, 3, 213-217, doi:10.1038/nclimate1719, 2013.

Farmer, D., Sivapalan, M., and Jothityangkoon, C.: Climate, soil, and vegetation controls upon the variability of water balance in temperate and semiarid landscapes: Downward approach to water balance analysis, Water Resour. Res., 39, 1035, doi:10.1029/2001WR000328, 2003.

Harman, C. and Troch, P. A.: What makes Darwinian hydrology "Darwinian"? Asking a different kind of question about landscapes, Hydrol. Earth Syst. Sci., 18, 417-433, doi:10.5194/hess18-417-2014, 2014.

Harr, R.: Water flux in soil and subsoil on a steep forested slope, J. Hydrol., 33, 37-58, doi:10.1016/0022-1694(77)90097-X, 1977.

Helsel, D. R. and Hirsch, R. M.: Statistical Methods in water resources, in: Techniques of Water-Resources Investigations, book 4, chap. A3, US Geological Survey, Reston, VA, 522 pp., 2002.

Henderson, F. M.: Open Channel Flow, Macmillan, New York, 522 pp., 1966.

Howard, A. D.: Theoretical model of optimal drainage networks, Water Resour. Res., 26, 2107-2117, doi:10.1029/WR026i009p02107, 1990.

Ibbitt, R. P.: Evaluation of optimal channel network and river basin heterogeneity concepts using measured flow and channel properties, J. Hydrol., 196, 119-138, doi:10.1016/S00221694(96)03293-3, 1997.

Jaramillo, F. and Destouni, G.: Comment on "Planetary boundaries: Guiding human development on a changing planet", Science, 348, 1217-1217, doi:10.1126/science.aaa9629, 2015.

Jaramillo, F., Prieto, C., Lyon, S. W., and Destouni, G.: Multimethod assessment of evapotranspiration shifts due to nonirrigated agricultural development in Sweden, J. Hydrol., 484, 55-62, doi:10.1016/j.jhydrol.2013.01.010, 2013.

Kirchner, J. W.: Catchments as simple dynamical systems: Catchment characterization, rainfall-runoff modeling, and doing hydrology backward, Water Resour. Res., 45, 1-34, doi:10.1029/2008WR006912, 2009.

Krakauer, N. Y. and Temimi, M.: Stream recession curves and storage variability in small watersheds, Hydrol. Earth Syst. Sci., 15, 2377-2389, doi:10.5194/hess-15-2377-2011, 2011.

Leopold, L. and Maddock Jr., T.: The Hydraulic Geometry of Stream Channels and Some Physiographic Implications, US Geological Survey Professional Paper 252, U.S. Government Printing Office, Washington D.C., 57 pp., 1953.

Lyon, S. W. and Destouni, G.: Changes in catchment-scale recession flow properties in response to permafrost thawing in the Yukon River Basin, Int. J. Climatol., 30, 2138-2145, doi:10.1002/joc.1993, 2010 . 
Lyon, S. W. and Troch, P. A.: Hillslope subsurface flow similarity: real-world tests of the hillslope Péclet number, Water Resour. Res., 43, W07450, doi:10.1029/2006WR005323, 2007.

Lyon, S. W., Destouni, G., Giesler, R., Humborg, C., Mörth, M., Seibert, J., Karlsson, J., and Troch, P. A.: Estimation of permafrost thawing rates in a sub-arctic catchment using recession flow analysis, Hydrol. Earth Syst. Sci., 13, 595-604, doi:10.5194/hess-13-595-2009, 2009.

Lyon, S. W., Nathanson, M., Spans, A., Grabs, T., Laudon, H., Temnerud, J., Bishop, K. H., and Seibert, J.: Specific discharge variability in a boreal landscape, Water Resour. Res., 48, 1-13, doi:10.1029/2011WR011073, 2012.

Lyon, S. W., Koutsouris, A., Scheibler, F., Jarsjö, J., Mbanguka, R., Tumbo, M., Robert, K. K., Sharma, A. N., and van der Velde, Y.: Interpreting characteristic drainage timescale variability across Kilombero Valley, Tanzania, Hydrol. Process., 29, 1912-1924, doi:10.1002/hyp.10304, 2015.

Malvicini, C. F., Steenhuis, T. S., Walter, M. T., Parlange, J.-Y., and Walter, M. F.: Evaluation of spring flow in the uplands of Matalom, Leyte, Philippines, Adv. Water Resour., 28, 1083-1090, doi:10.1016/j.advwatres.2004.12.006, 2005.

McMillan, H., Gueguen, M., Grimon, E., Woods, R., Clark, M. and Rupp, D. E.: Spatial variability of hydrological processes and model structure diagnostics in a $50 \mathrm{~km}^{2}$ catchment, Hydrol. Process., 28, 4896-4913, doi:10.1002/hyp.9988, 2014.

Mendoza, G. F., Steenhuis, T. S., Walter, M., and Parlange, J.-Y.: Estimating basin-wide hydraulic parameters of a semi-arid mountainous watershed by recession-flow analysis, J. Hydrol., 279, 57-69, doi:10.1016/S0022-1694(03)00174-4, 2003.

Molnar, P. and Ramirez, J. A.: On downstream hydraulic geometry and optimal energy expenditure: case study of the Ashley and Taieri Rivers, J. Hydrol., 259, 105-115, doi:10.1016/S00221694(01)00590-X, 2002.

Parker, C. and Chartres, C.: The effects of recent land use changes on red podzolic soils near Sydney, NSW, Australia, Catena, 10, 61-76, doi:10.1016/S0341-8162(83)80005-8, 1983

Parlange, J.-Y., Stagnitti, F., Heilig, A., Szilagyi, J., Parlange, M. B., Steenhuis, T. S., Hogarth, W. L., Barry, D. a., and Li, L.: Sudden drawdown and drainage of a horizontal aquifer, Water Resour. Res., 37, 2097-2101, doi:10.1029/2000WR000189, 2001.

Rockström, J., Steffen, W., Noone, K., Persson, A., Chapin, F. S., Lambin, E. F., Lenton, T. M., Scheffer, M., Folke, C., Schellnhuber, H. J., Nykvist, B., de Wit, C. A., Hughes, T., van der Leeuw, S., Rodhe, H., Sörlin, S., Snyder, P. K., Costanza, R., Svedin, U., Falkenmark, M., Karlberg, L., Corell, R. W., Fabry, V. J., Hansen, J., Walker, B., Liverman, D., Richardson, K., Crutzen, P., and Foley, J. A.: A safe operating space for humanity, Nature, 461, 472-475, doi:10.1038/461472a, 2009.

Rodríguez-Iturbe, I., Rinaldo, A., Rigon, R., Bras, R. L., Marani, A., and Ijjász-Vásquez, E.: Energy dissipation, runoff production, and the three-dimensional structure of river basins, Water Resour. Res., 28, 1095-1103, doi:10.1029/91WR03034, 1992.

Rupp, D. E. and Selker, J. S.: Drainage of a horizontal Boussinesq aquifer with a power law hydraulic conductivity profile, Water Resour. Res., 41, W11422, doi:10.1029/2005WR004241, 2005.

Rupp, D. E. and Selker, J. S.: Information, artifacts, and noise in $\mathrm{d} Q / \mathrm{d} t-Q$ recession analysis, Adv. Water Resour., 29, 154-160, doi:10.1016/j.advwatres.2005.03.019, 2006a.
Rupp, D. E. and Selker, J. S.: On the use of the Boussinesq equation for interpreting recession hydrographs from sloping aquifers, Water Resour. Res., 42, W12421, doi:10.1029/2006WR005080, $2006 b$.

Saaltink, R., van der Velde, Y., Dekker, S. C., Lyon, S. W., and Dahlke, H. E.: Societal, land cover and climatic controls on river nutrient flows into the Baltic Sea, J. Hydrol., 1, 44-56, doi:10.1016/j.ejrh.2014.06.001, 2014.

Savenije, H. H. G., Hoekstra, A. Y., and van der Zaag, P.: Evolving water science in the Anthropocene, Hydrol. Earth Syst. Sci., 18, 319-332, doi:10.5194/hess-18-319-2014, 2014.

Schaefli, B., Harman, C. J., Sivapalan, M., and Schymanski, S. J.: HESS Opinions: Hydrologic predictions in a changing environment: behavioral modeling, Hydrol. Earth Syst. Sci., 15, 635646, doi:10.5194/hess-15-635-2011, 2011.

Shaw, S. B. and Riha, S. J.: Examining individual recession events instead of a data cloud: Using a modified interpretation of $\mathrm{d} Q / \mathrm{d} t-Q$ streamflow recession in glaciated watersheds to better inform models of low flow, J. Hydrol., 434-435, 46-54, doi:10.1016/j.jhydrol.2012.02.034, 2012.

Shaw, S. B., McHardy, T. M., and Riha, S. J.: Evaluating the influence of watershed moisture storage on variations in base flow recession rates during prolonged rain-free periods in mediumsized catchments in New York and Illinois, USA, Water Resour. Res., 49, 6022-6028, doi:10.1002/wrcr.20507, 2013.

Sivapalan, M., Thompson, S. E., Harman, C. J., Basu, N. B., and Kumar, P.: Water cycle dynamics in a changing environment: improving predictability through synthesis, Water Resour. Res., 47, W00J01, doi:10.1029/2011WR011377, 2011.

Sivapalan, M., Savenije, H. H. G., and Blöschl, G.: Sociohydrology: a new science of people and water, Hydrol. Process., 26, 1270-1276, doi:10.1002/hyp.8426, 2012.

Sjöberg, Y., Frampton, A., and Lyon, S. W.: Using streamflow characteristics to explore permafrost thawing in northern Swedish catchments, Hydrogeol. J., 21, 121-131, doi:10.1007/s10040012-0932-5, 2012.

Soulsby, C., Tetzlaff, D., Rodgers, P., Dunn, S., and Waldron, S.: Runoff processes, stream water residence times and controlling landscape characteristics in a mesoscale catchment: an initial evaluation, J. Hydrol., 325, 197-221, doi:10.1016/j.jhydrol.2005.10.024, 2006.

Steffen, W., Richardson, K., Rockstrom, J., Cornell, S. E., Fetzer, I., Bennett, E. M., Biggs, R., Carpenter, S. R., de Vries, W., de Wit, C. A., Folke, C., Gerten, D., Heinke, J., Mace, G. M., Persson, L. M., Ramanathan, V., Reyers, B., and Sorlin, S.: Planetary boundaries: guiding human development on a changing planet, Science, 347, 1259855-1-1259855-10, doi:10.1126/science.1259855, 2015.

Stoelzle, M., Stahl, K., and Weiler, M.: Are streamflow recession characteristics really characteristic?, Hydrol. Earth Syst. Sci., 17, 817-828, doi:10.5194/hess-17-817-2013, 2013.

Szilagyi, J., Parlange, M. B., and Albertson, J. D.: Recession flow analysis for aquifer parameter determination, Water Resour. Res., 34, 1851-1857, doi:10.1029/98WR01009, 1998.

Szilagyi, J., Gribovszki, Z., and Kalicz, P.: Estimation of catchmentscale evapotranspiration from baseflow recession data: numerical model and practical application results, J. Hydrol., 336, 206-217, doi:10.1016/j.jhydrol.2007.01.004, 2007. 
Tague, C. and Grant, G. E.: A geological framework for interpreting the low-flow regimes of Cascade streams, Willamette River Basin, Oregon, Water Resour. Res., 40, W04303, doi:10.1029/2003WR002629, 2004.

Tetzlaff, D., Seibert, J., and Soulsby, C.: Inter-catchment comparison to assess the influence of topography and soils on catchment transit times in a geomorphic province, the Cairngorm mountains, Scotland, Hydrol. Process., 23, 1874-1886, doi:10.1002/hyp.7318, 2009.

Troch, P. A., Mancini, M., Paniconi, C., and Wood, E. F.: Evaluation of a distributed catchment scale water balance model, Water Resour. Res., 29, 1805-1817, doi:10.1029/93WR00398, 1993.

Troch, P. A., Berne, A., Bogaart, P., Harman, C., Hilberts, A. G. J., Lyon, S. W., Paniconi, C., Pauwels, V. R. N., Rupp, D. E., Selker, J. S., Teuling, A. J., Uijlenhoet, R., and Verhoest, N. E. C.: The importance of hydraulic groundwater theory in catchment hydrology: the legacy of Wilfried Brutsaert and Jean-Yves Parlange, Water Resour. Res., 49, 5099-5116, doi:10.1002/wrcr.20407, 2013a.

Troch, P. A., Carrillo, G., Sivapalan, M., Wagener, T., and Sawicz, K.: Climate-vegetation-soil interactions and long-term hydrologic partitioning: signatures of catchment co-evolution, Hydrol. Earth Syst. Sci., 17, 2209-2217, doi:10.5194/hess-17-22092013, 2013b.

Troch, P. A., Lahmers, T., Meira, A., Mukherjee, R., Pedersen, J. W., Roy, T., and Valdés-Pineda, R.: Catchment coevolution: a useful framework for improving predictions of hydrological change?, Water Resour. Res., 51, 4903-4922, doi:10.1002/2015WR017032, 2015.

Tucker, G. E. and Bras, R. L.: Hillslope processes, drainage density, and landscape morphology, Water Resour. Res., 34(10), 27512764, doi:10.1029/98WR01474, 1998.
Ulén, B. and Jakobsson, C.: Critical evaluation of measures to mitigate phosphorus losses from agricultural land to surface waters in Sweden, Sci. Total Environ., 344, 37-50, doi:10.1016/j.scitotenv.2005.02.004, 2005.

van der Velde, Y., Lyon, S. W., and Destouni, G.: Data-driven regionalization of river discharges and emergent land coverevapotranspiration relationships across Sweden, J. Geophys. Res.-Atmos., 118, 2576-2587, doi:10.1002/jgrd.50224, 2013a.

van der Velde, Y., Vercauteren, N., Jaramillo, F., Dekker, S. C., Destouni, G., and Lyon, S. W.: Exploring hydroclimatic change disparity via the Budyko framework, Hydrol. Process., 28, 4110 4118, doi:10.1002/hyp.9949, 2013b.

van Dijk, A. I. J. M.: Climate and terrain factors explaining streamflow response and recession in Australian catchments, Hydrol. Earth Syst. Sci., 14, 159-169, doi:10.5194/hess-14-159-2010, 2010.

Vogel, R. M. and Kroll, C. N.: Regional geohydrologic-geomorphic relationships for the estimation of low-flow statistics, Water Resour. Res., 28, 2451-2458, doi:10.1029/92WR01007, 1992.

Wittenberg, H.: Baseflow recession and recharge as nonlinear storage processes, Hydrol. Process., 13, 715-726, 1999.

Zecharias, Y. B. and Brutsaert, W.: Recession characteristics of groundwater outflow and base flow from mountainous watersheds, Water Resour. Res., 24, 1651-1658, doi:10.1029/WR024i010p01651, 1988.

Zimmermann, B. and Elsenbeer, H.: Spatial and temporal variability of soil saturated hydraulic conductivity in gradients of disturbance, J. Hydrol., 361, 78-95, doi:10.1016/j.jhydrol.2008.07.027, 2008.

Zimmermann, B., Elsenbeer, H., and De Moraes, J. M.: The influence of land-use changes on soil hydraulic properties: implications for runoff generation, Forest Ecol. Manag., 222, 29-38, doi:10.1016/j.foreco.2005.10.070, 2006. 